\title{
Patterns in atmospheric carbonaceous aerosols in China: emission estimates and observed concentrations
}

\author{
H. Cui ${ }^{1}$, P. Mao ${ }^{1}$, Y. Zhao ${ }^{1,2}$, C. P. Nielsen ${ }^{3}$, and J. Zhang ${ }^{2,4}$ \\ ${ }^{1}$ State Key Laboratory of Pollution Control \& Resource Reuse and School of the Environment, Nanjing University, \\ 163 Xianlin Ave., Nanjing, Jiangsu 210023, China \\ ${ }^{2}$ Jiangsu Collaborative Innovation Center of Atmospheric Environment and Equipment Technology (CICAEET), \\ Nanjing University of Information Science \& Technology, Jiangsu 210044, China \\ ${ }^{3}$ Harvard China Project, School of Engineering and Applied Sciences, Harvard University, 29 Oxford St, \\ Cambridge, MA 02138, USA \\ ${ }^{4}$ Jiangsu Provincial Academy of Environmental Science, 176 North Jiangdong Rd., Nanjing, Jiangsu 210036, China
}

Correspondence to: Y. Zhao (yuzhao@ nju.edu.cn)

Received: 6 January 2015 - Published in Atmos. Chem. Phys. Discuss.: 25 March 2015

Revised: 1 July 2015 - Accepted: 20 July 2015 - Published: 6 August 2015

\begin{abstract}
China is experiencing severe carbonaceous aerosol pollution driven mainly by large emissions resulting from intensive use of solid fuels. To gain a better understanding of the levels and trends of carbonaceous aerosol emissions and the resulting ambient concentrations at the national scale, we update an emission inventory of anthropogenic organic carbon (OC) and elemental carbon (EC) and employ existing observational studies to analyze characteristics of these aerosols including temporal, spatial, and size distributions, and the levels and shares of secondary organic carbon (SOC) in total OC. We further use ground observations to test the levels and inter-annual trends of the calculated national and provincial emissions of carbonaceous aerosols, and propose possible improvements in emission estimation for the future. The national OC emissions are estimated to have increased $29 \%$ from $2000(2127 \mathrm{Gg})$ to $2012(2749 \mathrm{Gg})$ and $\mathrm{EC}$ by $37 \%$ (from 1356 to $1857 \mathrm{Gg}$ ). The residential, industrial, and transportation sectors contributed an estimated 74-78, 1721 , and $4-6 \%$ of the total emissions of OC, respectively, and $49-55,30-34$, and $14-18 \%$ of EC. Updated emission factors (EFs) based on the most recent local field measurements, particularly for biofuel stoves, led to considerably lower emissions of OC compared to previous inventories. Compiling observational data across the country, higher concentrations of $\mathrm{OC}$ and $\mathrm{EC}$ are found in northern and inland cities, while higher OC / EC ratios are found in southern sites, due to the joint effects of primary emissions and meteorology. Higher
\end{abstract}

OC / EC ratios are estimated at rural and remote sites compared to urban ones, attributed to more emissions of OC from biofuel use, more biogenic emissions of volatile organic compound (VOC) precursors to SOC, and/or transport of aged aerosols. For most sites, higher concentrations of OC, EC, and SOC are observed in colder seasons, while SOC / OC is reduced, particularly at rural and remote sites, attributed partly to weaker atmospheric oxidation and SOC formation compared to summer. Enhanced SOC formation from oxidization and anthropogenic activities like biomass combustion is judged to have crucial effects on severe haze events characterized by high particle concentrations. Several observational studies indicate an increasing trend in ambient OC / EC (but not in OC or EC individually) from 2000 to 2010 , confirming increased atmospheric oxidation of OC across the country. Combining the results of emission estimation and observations, the improvement over prior emission inventories is indicated by inter-annual comparisons and correlation analysis. It is also indicated, however, that the estimated growth in emissions might be faster than observed growth, and that some sources with high primary OC / EC, such as burning of biomass, are still underestimated. Further studies to determine changing EFs over time in the residential sector and to compare to other measurements, such as satellite observations, are thus suggested to improve understanding of the levels and trends of primary carbonaceous aerosol emissions in China. 


\section{Introduction}

Atmospheric carbonaceous species including organic carbon (OC) and elemental carbon (EC) are significant, sometimes dominant, components of fine particulate concentrations, accounting for $20-50 \%$ of $\mathrm{PM}_{2.5}$ mass in highly polluted atmospheres (Park et al., 2001). Sometimes referred to as black carbon (BC), EC mainly originates from incomplete combustion of fossil fuels and biomass. As a complex mixture of hundreds of individual compounds, OC can be both emitted directly from combustion sources (described as primary organic carbon, POC) and formed through photochemical reactions in which gaseous volatile organic compounds (VOCs) are converted to pollutants in the particle phase (described as secondary organic carbon, SOC).

Because of the important roles OC and EC play in global climate, atmospheric chemistry, and environmental health (Engling and Gelencser, 2010; Mauderly and Chow, 2008), increasing attention has been paid to pollution comprised of atmospheric carbonaceous aerosols around the world, and especially in China due to its rapid economic growth and urbanization over the last 30 years. China is now estimated to have become the largest energy-consuming country, and accounted for over $50 \%$ of global coal use in 2013 (BP, 2014). Severe haze events characterized by enhanced levels of airborne particulate matter (PM) and poor visibility have become a central challenge in air quality management and one of the highest profile issues in the country (Huang et al., 2014; Q. Zhang et al., 2012). Very high average concentrations of OC and EC have been found in large cities of China compared to other cities around the world, particularly in the most intensively developed areas including the BeijingTianjin-Hebei region (commonly called "Jing-Jin-Ji", abbreviated JJJ here) (Dan et al., 2004; Duan et al., 2005; Li and Bai, 2009; Zhang et al., 2007; P. Zhao et al., 2013; Yang et al., 2011a), the Yangtze River Delta (YRD) region (Feng et al. 2006a, b, 2013; Feng et al., 2009; Huang et al., 2013; Y. Wang et al., 2010), and the Pearl River Delta (PRD) region (Cao et al., 2003a, b, 2004; Feng et al., 2006b; H. Huang et al., 2012).

Given China's large share of worldwide emissions and regional PM pollution, great efforts have been made for more than 10 years to quantify China's emissions of carbonaceous aerosols using gradually improving bottom-up methods, from global (Bond et al., 2004, 2007), continental (Streets et al., 2003; Ohara et al., 2007; Q. Zhang et al., 2009; Kurokawa et al., 2013), or national perspectives (Streets et al., 2001; Lei et al., 2011; Lu et al., 2011; Zhao et al., 2011; Y. Zhao et al., 2013). Limited by data access, however, previous inventory studies of China's EC and OC emissions are considered highly uncertain (Streets et al., 2003; Zhang et al., 2009), as indicated by top-down constraints through chemical transport modeling (Fu et al., 2012). Because of routine publication delays of statistics that are essential for emission inventory development, including those for energy consump- tion and industrial production, efforts to provide timely emission estimates sometimes rely on predicted or extrapolated activity data based on historic information or "fast-track" data that lack official validation (Streets et al., 2001; Zhang et al., 2009; Lu et al., 2011). Another important reason limiting the accuracy of current estimates is strong dependence on emission factors (EFs) derived from developed countries, particularly for residential heating and cooking stoves, for which the combustion conditions can differ considerably between countries. In recent years, increasing domestic field measurements of local EFs for EC and OC have been conducted, but few of these updated EFs have been applied in current estimates of emissions, which predate much of the fieldwork. In addition, some emission sources, e.g., off-road transportation and biomass open burning, have been omitted in some inventories, making direct comparisons and evaluation of different studies difficult. With all of these various limitations, the uncertainties of China's primary carbonaceous emissions, particularly over long periods, have seldom been quantified except for in one study (Lu et al., 2011).

Aside from the trends in emissions, regional and local pollution levels of carbonaceous aerosols across the country have been drawing increased attention. Although studies of ambient concentrations of carbonaceous aerosols in China began in the 1980 s, continuous observations did not begin until the mid-1990s (Cao et al., 2007). Using the methods of thermal-optical reflection (TOR) or thermal-optical transmission (TOT), measurements of OC and EC as airborne particles have now been conducted in urban, rural, and remote sites for typical cities and seasons. Most studies, however, focused only on a single city (except for a few including Cao et al., 2007; X. Y. Zhang et al., 2008, 2012) or relatively short periods (except for Yang et al., 2011a). Without analyses combining results of multiple studies, pollution characteristics and trends of carbonaceous aerosols over relatively long periods remain unclear for the country. Lacking trends of ambient pollution levels, moreover, observations have seldom been linked to emission inventory studies. Thus, they have contributed little to verification of estimated emissions, limiting improvement of emission estimates.

In this work, therefore, EC and OC emissions of China for 2000-2012 are estimated with a consistent framework that encompasses all anthropogenic sources: fossil fuel combustion, biofuel combustion, and biomass open burning. Newly published data from domestic field measurements are incorporated into the framework to update the emission factors, with the uncertainties carefully quantified. Based on thorough review of existing observation studies, the spatial and seasonal distributions, the long-term trends of OC and EC concentrations, and the level of SOC formation are analyzed to provide a comprehensive picture of carbonaceous aerosol pollution in China during a period of rapid economic development and improved pollution controls. Using available observations, the accuracy of estimated levels and trends of primary carbonaceous aerosol emissions is evaluated, and fur- 
ther improvement of emission inventory research is accordingly proposed.

\section{Emissions of primary carbonaceous aerosols}

\subsection{Methods and activity data}

The method to develop bottom-up emission inventories has been described in previous work (Zhao et al., 2011, 2012; Y. Zhao et al., 2013). The emission sources mainly fall into four sector categories: coal-fired power plants (CPP), industry (IND), transportation (TRA; including on-road and off-road subcategories), and the residential and commercial sectors (RES; including fossil fuel and biomass combustion subcategories). IND is further divided into cement production (CEM), iron and steel plants (ISP), other industrial boilers (OIB), and other industrial processes (PRO). Residential biomass combustion contains household biofuel use and open biomass burning (forest fire not included). Using Eq. (1), the EC and OC emissions are calculated by province and sector and then aggregated to the national level:

$$
E_{i, j, t}=\sum_{k} \sum_{m} \sum_{n} \mathrm{AL}_{j, k, m, t} \times \mathrm{EF}_{i, j, k, m, n} \times R_{j, k, m, n, t},
$$

where $i, j, k, m, n$, and $t$ stand for species (EC and OC), province, sector, fuel type, emission control technology and year, respectively; AL is the activity level, either energy consumption or industrial production; $\mathrm{EF}$ is the emission factor; and $R$ is the penetration rate of emission control technology.

For small coal stoves, biofuel cook stoves, and biomass open burning, $\mathrm{EF}_{\mathrm{EC}}$ and $\mathrm{EF}_{\mathrm{OC}}$ are derived from published data of local field measurements, as described in Sect. 2.2. For most other sources, $\mathrm{EF}_{\mathrm{EC}}$ and $\mathrm{EF}_{\mathrm{OC}}$ are estimated as the products of the $\mathrm{PM}_{2.5}$ emission factor and the mass fraction of EC and OC for corresponding sources:

$$
\begin{aligned}
\mathrm{EF}_{i, j, k, m, n} & =\mathrm{EF}_{\mathrm{PM}, j, k, m, n} \times f_{\mathrm{PM}_{2.5}, k, m} \\
& \times\left(1-\eta_{\mathrm{PM}_{2.5}, k, m, n}\right) \times F_{i, k, m},
\end{aligned}
$$

where $\mathrm{EF}_{\mathrm{PM}}$ is the unabated emission factor for $\mathrm{PM} ; f_{\mathrm{PM}_{2.5}}$ is the $\mathrm{PM}_{2.5}$ mass fraction of total PM; $\eta$ is the removal efficiency of the emission control technology; and $F$ is the EC or OC mass fraction of $\mathrm{PM}_{2.5}$.

Compared to previous inventories, improvements are made in the method of current work. First, activity data of certain categories (e.g., biofuel use) are updated with the latest available information, as described later in this section. Second, more detailed classification is applied for residential combustion to better differentiate the emission characteristics of various subcategories. Third, the emission factor database is modified compared to previous work (Zhao et al., 2011; Lu et al., 2011), with the most recent results from local field measurements incorporated. Clear difference in emission factors for given sources is found from previous inventory studies. Finally, the temporal and spatial variability in emission factors is better understood with more local information combined. The details for the latter three will be provided in Sect. 2.3.

The uncertainties of this emission inventory are quantified with Monte Carlo simulation as described in Zhao et al. (2011). All of the input parameters of activity levels and emission factors, with corresponding probability distributions, are placed in a Monte Carlo framework, and 10000 simulations are performed. The uncertainties of annual OC and $\mathrm{EC}$ emissions and their grow rates, expressed as $95 \%$ confidence intervals (CIs) around the central estimates, are generated by sector. The parameters that are most significant in determining the uncertainties are also identified according to their contributions to the variance of emissions.

Activity data for 2000-2012 are compiled annually by sector from a variety of data sources. The fossil fuel consumption and industrial production are obtained at the provincial level from Chinese official energy (NBS, 2013a) and industrial economic statistics (NBS, 2013b). For some industrial sources lacking official statistics, such as brick and tile making, production data are estimated based on data from relevant industrial associations. To avoid double counting, the fuel consumption by OIB is estimated by subtracting the fuel consumed by CEM, ISP, and PRO from fuel consumed by the whole industry (Zhao et al., 2012). In addition to coal combustion, wood combustion by industrial sector is taken from Chen et al. (2013). The annual biofuel use for residential stoves before 2008 is taken from official statistics (NBS, 2013a), and those for the following years are from unpublished data by Ministry of Agriculture, since official statistics stopped reporting the data in 2008 (Chen et al., 2013). The biomass combusted in open fields is calculated as a product of grain production, waste-to-grain ratio, and the percentage of residual material burned in the field, as described in Zhao et al. $(2011,2012)$.

\subsection{Emission factors}

Of all the sectors, the residential and commercial sector is the largest contributor of national EC and OC emissions. Parameters related with emission factors are estimated to contribute most to the uncertainties of emissions, attributed mainly to a lack of relevant local field studies (Lu et al., 2011; Y. Zhao et al., 2013). Widely used by Chinese rural families for boiling water, heating, and cooking, small coal and biofuel stoves are the main emission sources of the sector. In recent years, a number of field studies explored EC and/or OC emission levels from those local sources (Shen et al., 2010, 2012, 2013; Wei et al., 2014). Combined with results of similar studies that were published earlier (Chen et al., 2005, 2006, 2009; Zhi et al., 2008, 2009; Y. Zhang et al., 2008; Cao et al., 2008; Li et al., 2009), EFs are shown to vary significantly among emission sources using different coal types. For example, the EC EFs from briquette combustion are generally smaller than those from chuck combustion. In this work, therefore, 
(a)

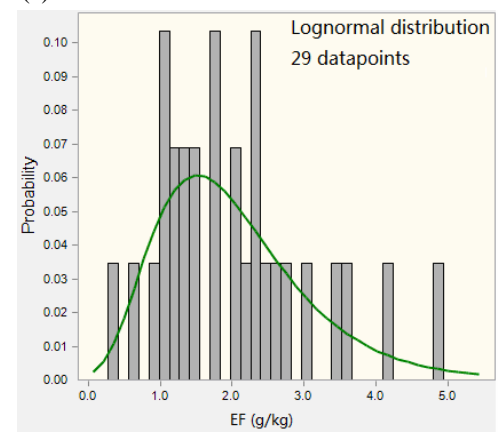

(c)

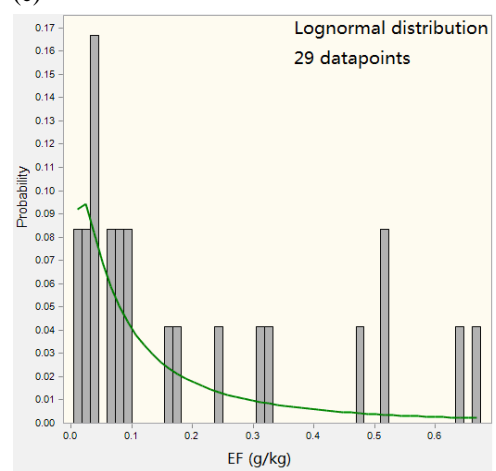

(b)

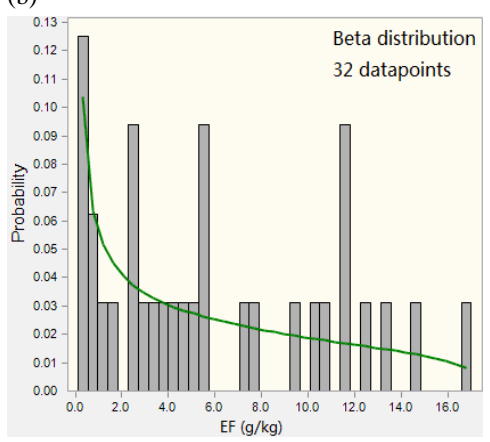

Figure 1. Probability distributions of emission factors for combustion in small stoves: (a) OC from crop waste burning; (b) OC from bituminous chunk-coal burning; and (c) EC from bituminous briquette burning.

coal stoves are further broken down into those burning anthracite briquettes, bituminous briquettes, anthracite chunk coal, and bituminous chunk coal, and the EF for each type is determined based on corresponding field measurements. For biofuel combustion, the difference in stove design between northern and southern China is taken into account in this work; e.g., field measurements of "kangs" (traditional brick bed stoves) which are limited to northern China, are excluded for EF analysis for southern provinces. For EFs with adequate domestic measurement data, a probability distribution is fitted using the statistical software package Crystal Ball and the Kolmogorov-Smirnov test for the goodnessof-fit $(p=0.05)$. As shown in Fig. 1, the OC EFs of crop wastes and bituminous chunk coal, and EC EF of bituminous briquettes burned in stoves pass the test and their probability distributions are presented. For EFs with insufficient observation data, and those that fail to pass the goodness-of-fit test, probability distributions must be assumed following our previous work (Zhao et al., 2011). Detailed information on EC and OC EFs of coal and biofuel stoves is summarized in Table 1. From 2000 to 2012, the annual fraction of briquette use in residential coal combustion varied between 5 and $12 \%$, leading to small changes in average EC EF in the period. As shown in Fig. S1 in the Supplement, the trends in average EC EF of residential coal combustion and the national fraction of briquette use for 2000-2012 are found to be inconsistent with each other. For open biomass burning the EFs are taken from limited domestic measurements by Li et al. (2007), and uniform distributions (0.2-0.7 and 0.4$7.3 \mathrm{~kg} \mathrm{t}^{-1}$ for EC and OC, respectively) have to be conservatively assumed as stated in Zhao et al. (2011), attributed mainly to the irregularity values from the tests.

For other sectors, few studies based on EC and/or OC EF measurement have been published in recent years and the EFs summarized in Y. Zhao et al. (2013) are used in this study in most cases. For transportation, the results from onroad measurements by Huo et al. (2012), Wu et al. (2012), and Fu et al. (2013) are incorporated into the emission factor database developed by Y. Zhao et al. (2013). The $\mathrm{PM}_{2.5}$ $\mathrm{EF}$ for light-duty diesel trucks meeting stage I emission standards is updated from 3.4 to $2.3 \mathrm{~g} \mathrm{~kg}^{-1}$ and that for inland shipping from 1.1 to $2.2 \mathrm{~g} \mathrm{~kg}^{-1}$, leading to corresponding changes of the EC and OC EFs. Table S1 in the Supplement provides the EF database for transportation.

\subsection{Temporal trends, spatial distribution, and uncertainties of emissions}

The calculated annual total EC and OC emissions with their uncertainties for 2000-2012 are presented in Fig. 2a and $\mathrm{b}$, respectively, and the emission uncertainties by sector for 2012 are summarized in Table 2. The uncertainties of EC and OC emissions for 2012 are estimated at -27 to $127 \%$ and -34 to $90 \%$ (expressed as relative changes of $95 \%$ CI to 
Table 1. EC and OC emission factors for coal and biofuel burned in small stoves $\left(\mathrm{g} \mathrm{kg}^{-1}\right)$. The values in parentheses indicate the range (for uniform distribution), $95 \% \mathrm{CI}$ (for beta distribution), or standard deviation (SD; for lognormal distribution) of the emission factor.

\begin{tabular}{|c|c|c|c|c|}
\hline & \multicolumn{2}{|r|}{$\mathrm{EF}_{\mathrm{EC}}$} & \multicolumn{2}{|r|}{$\mathrm{EF}_{\mathrm{OC}}$} \\
\hline & Value & Distribution & Value & Distribution \\
\hline Anthracite briquette & 0.006 & $\begin{array}{l}\text { Uniform } \\
(0.000-0.012)\end{array}$ & 0.20 & $\begin{array}{l}\text { Uniform } \\
(0.04-0.36)\end{array}$ \\
\hline Bituminous briquette & 0.24 & $\begin{array}{l}\text { Lognormal } \\
\text { (SD: 0.53) }\end{array}$ & 5.16 & $\begin{array}{l}\text { Uniform } \\
(0-13.8)\end{array}$ \\
\hline Anthracite chunk coal & 0.03 & $\begin{array}{l}\text { Uniform } \\
(0-0.04)\end{array}$ & 0.25 & $\begin{array}{l}\text { Uniform } \\
(0.03-0.47)\end{array}$ \\
\hline Bituminous chunk coal & 3.13 & $\begin{array}{l}\text { Uniform } \\
(0-16.9)\end{array}$ & 4.94 & $\begin{array}{l}\text { Beta } \\
(0.12-14.98)\end{array}$ \\
\hline Crop wastes as biofuel & 0.97 & $\begin{array}{l}\text { Lognormal } \\
\text { (SD: 0.94) }\end{array}$ & 2.04 & $\begin{array}{l}\text { Lognormal } \\
\text { (SD: 1.09) }\end{array}$ \\
\hline Firewood & 0.88 & $\begin{array}{l}\text { Lognormal } \\
\text { (SD: } 1.15 \text { ) }\end{array}$ & 1.0 & $\begin{array}{l}\text { Lognormal } \\
\text { (SD: 1.29) }\end{array}$ \\
\hline
\end{tabular}

central estimates), respectively, and no significant variation or clear inter-annual trend is found for uncertainties of emissions for other years. The uncertainties estimated in current work are smaller than previous work (Lu et al., 2011; Zhao et al., 2011; Y. Zhao et al., 2013). The decreased uncertainties mainly appear in the residential sector and can be attributed to the updated emission factors that combine the most recent results from domestic field measurements. As shown in Table 2, the parameters associated with emission factors are estimated to contribute largest to the emission uncertainties in most cases, with an exception of the industrial sector in which the coke production level is also significant. The total emissions, both for EC and OC, are most sensitive to the emission factors of small coal stoves and crop waste burning.

Detailed information on emissions by source and year are provided in Table S2 in the Supplement. EC emissions are estimated to have increased by $37 \%$ from $1356 \mathrm{Gg}(95 \% \mathrm{CI}$ : 997-2914) in 2000 to 1857 (95\% CI: 1356-4221) in 2012, with relatively faster growth rates from 2000 to 2005 than the following years. Since 2005, improved emission control policies have resulted in reduced PM emission factors on average that partly counteracted the effects of increased activity levels. During the research period, the share of residential sector to total EC emissions is estimated to range 49-55\% for various years. The large contribution to total emissions is attributed mainly to generally inefficient combustion characteristics and a lack of effective emission controls in this sector. During the period, emissions from the residential sector increased by $34 \%$ (95\% CI: $23-61 \%)$, principally due to the growth of coal consumption. (Note the average EFs from coal combustion did not differ much between 2000 and 2012, attributed to similar rates of briquette use, as shown in Fig. S1.) The shares of the industry and transportation sectors
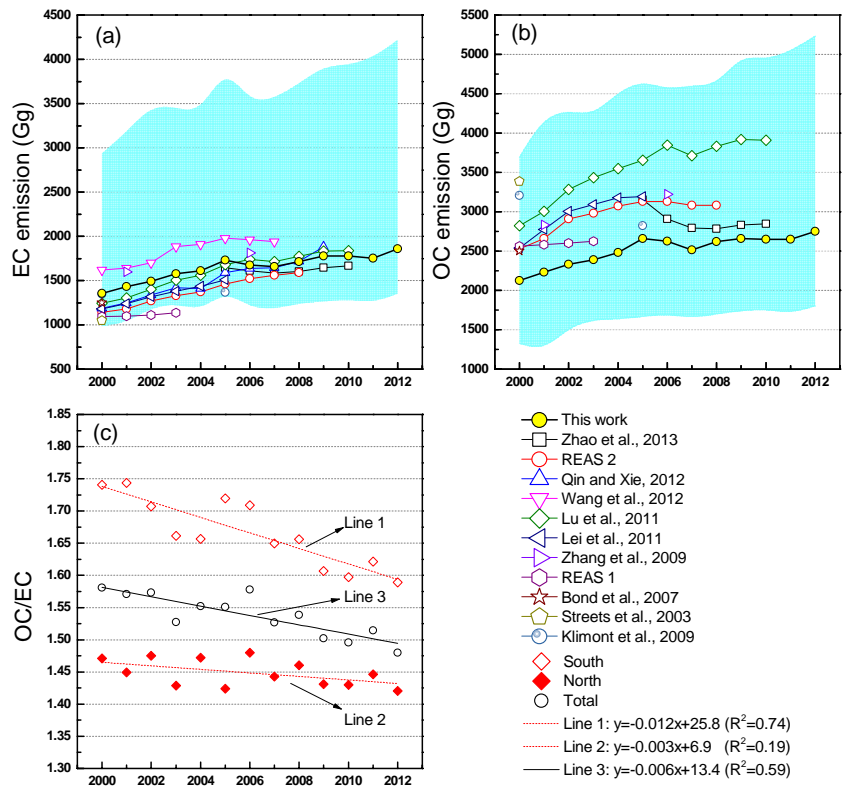

Figure 2. Inter-annual trends of (a) EC emissions, (b) OC emissions, and (c) ratios of $\mathrm{OC}$ to $\mathrm{EC}$ emissions, $(\mathrm{OC} / \mathrm{EC})_{\mathrm{emi}}$, for China from 2000 to 2012. The blue area indicates the $95 \%$ CIs estimated by this work. The definition of southern and northern provinces is indicated in Fig. 3.

are estimated to range $30-34 \%$, and $14-18 \%$, respectively, while very little emissions came from power plants because of the high combustion efficiency and well-implemented particle controls. Emissions of industry and transportation increased by 39 and $47 \%$, much slower than the growth of activity data, namely, $136 \%$ in industrial coal consumption 
and $204 \%$ in transportation oil consumption. This suggests improved emission control measures, e.g., the penetration of dust collectors with improved PM removal rates of industrial boilers, and the staged replacement of vehicles with stricter emission standards required by the national regulations.

OC emissions, shown in Fig. 2b, are estimated to have increased $29 \%$ from $2127 \mathrm{Gg}(95 \%$ CI: 1356-3637) in 2000 to 2749 (95\% CI: 1814-5223) in 2012, and the inter-annual trend is similar to that of EC emissions. The share of residential, industrial, and transportation sectors are estimated to range $74-78,17-21$, and $4-6 \%$ to total emissions, respectively, and the emissions of those sectors grew by 30,25 , and $39 \%$ during the research period. In particular, the share of emissions from biofuel use and biomass open burning is estimated to range 55-61\%. As shown in Fig. 2c, the ratios of OC to EC emissions, (OC / EC) $)_{\mathrm{emi}}$, are estimated to have declined slightly from 1.58 (95\% CI: 0.81-2.31) in 2000 to 1.52 (95\% CI: $0.76-2.21$ ) in 2012 , with higher values in southern China (from 1.74 to 1.68 ) than northern China (from 1.47 to 1.42). The regional difference in $(\mathrm{OC} / \mathrm{EC})_{\mathrm{emi}}$ can be attributed mainly to different levels of biofuel and biomass combustion, the sources with relatively high ratios of OC to EC emissions. These two sources are estimated to have contributed around 50 and $60 \%$ to $\mathrm{OC}$ emissions in northern and southern China, respectively. Moreover, some kinds of stoves that are commonly used for heating in northern China, e.g., kangs, have lower OC to EC emission ratios than cook stoves, according to recent field measurements (Shen et al., 2010, 2013).

The inter-annual variability in (OC / EC) $\mathrm{emi}$ ( $4 \%$ between 2000 and 2012) is much smaller compared to its uncertainty, resulting mainly from the different analytical methods for measuring EFs included in the emission inventory. For residential combustion, as shown in Table S3 in the Supplement, $77 \%$ of the samples were analyzed with the TOT method, while the left with TOR. For industrial and transportation sectors, most studies applied TOR (Wang et al., 2009; Zhang et al., 2009a, b). As considerable discrepancies exist in OC / EC measurement with different, or even the same methods/protocols (Schmid et al., 2001; Schauer et al., 2003), the relatively small inter-annual variability of $(\mathrm{OC} / \mathrm{EC})_{\mathrm{emi}}$ in current emission inventory needs to be cautiously evaluated. In this work, the uncertainties of emissions and thereby $(\mathrm{OC} / \mathrm{EC})_{\mathrm{emi}}$ are dominated by parameters related to emission factors by source, as shown in Table 2. No inter-annual variation in those parameters is assumed during the research period, even though high uncertainties exist for them in any given year. The changes in emissions and $(\mathrm{OC} / \mathrm{EC})_{\mathrm{emi}}$ over time at the sector level are thus driven mainly by the varied activity levels and fractions of different emission sources, and they are less associated with the uncertainty for an individual year.

Relative changes in emissions of total primary carbonaceous aerosols (i.e., TC, equal to OC+EC) between 2000 and 2012 are indicated by province in Fig. 3. In contrast 


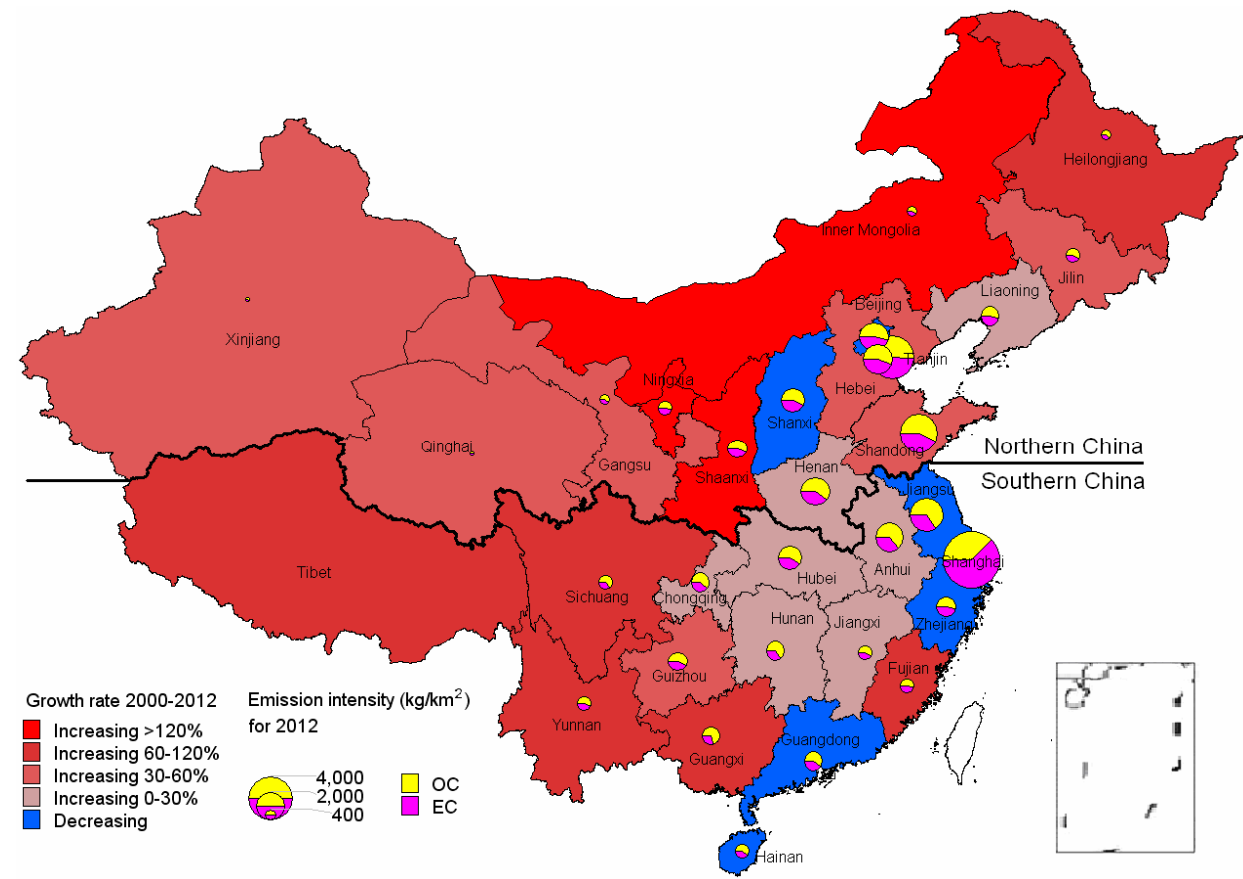

Figure 3. The provincial emission intensities of OC and EC in 2012 and relative changes of primary carbonaceous aerosol emissions (OC+EC) by province between 2000 and 2012.

to most provinces where growth in primary TC emissions is found, some economically advanced provinces including Beijing in the JJJ region, Shanghai, Jiangsu, and Zhejiang in the YRD region, and Guangdong in the PRD region, are estimated to have reduced their TC emissions during the last 10 years. The emission abatement in Beijing and Shanghai is attributed mainly to reduced energy consumption in the industrial sector, while that in Zhejiang and Jiangsu to reduced solid fuel use in the residential sector. Both situations indicate gradually improving economic and energy structures in the developed areas with relatively serious air pollution, and suggest increased attention to TC emission control in less economically advanced areas in the country. Shown in Fig. 3 as well are the emission intensities (i.e., emissions per unit territorial area) of TC by province in 2012, with the shares of OC and EC also indicated. In the most densely populated provinces in eastern and central China, larger intensities are generally found in the north than the south (provinces in the far north and west such as Xinjiang, Tibet, and Inner Mongolia are sparsely populated). In the populous and industrialized eastern part of the country, the annual average emission intensity of primary TC for 2000 to 2012 is estimated at 1.30 metric tons $\mathrm{km}^{-2}\left(\mathrm{t} \mathrm{TC} \mathrm{km}^{-2}\right)$ in northern provinces (Beijing, Tianjin, Hebei, Henan, Jilin, Liaoning, Shaanxi, Shandong, and Shanxi), 33\% higher than that for southern provinces (Jiangsu, Anhui, Shanghai, Zhejiang, Chongqing, Fujian, Guangdong, Guangxi, Guizhou, Hubei, Hunan, and Jiangxi) at $0.97 \mathrm{t} \mathrm{TC} \mathrm{km}^{-2}$. The differing emission levels of the north and south are a primary reason for different am- bient concentrations of carbonaceous aerosols, as discussed later in Sect. 3.1.

\subsection{Comparison with other emission inventory studies}

The comparisons of EC and OC emissions from this work and other studies are shown in Fig. 2. Note emissions of forest and savanna burning are excluded from the total emissions provided by original studies. In general, estimates of most studies are within the uncertainties evaluated in this work, with the exception of EC emissions by the Regional Emission Inventory in Asia (REAS) version 1 (REAS 1; Ohara et al., 2007). The inter-annual trends of EC emissions are in good agreement between studies, with relatively steady growth rates during 2000-2005 and then leveling off for the following years. However, our current EC estimates are hundreds of gigagrams higher than most others studies including Lei et al. (2011), Lu et al. (2011), Y. Zhao et al. (2011, 2013), Qin and Xie (2012), and REAS 2 (Kurokawa et al., 2013). The differences can be attributed to two reasons. First, some studies omitted some emission sources included here, e.g., off-road vehicles (Klimont et al., 2009; Qin and Xie, 2012; Kurokawa et al., 2013), biomass open burning (Lei et al., 2011; Kurokawa et al., 2013), and non-combustion industrial processes (Kurokawa et al., 2013). Second, emission factors for residential coal combustion used in Lu et al. (2011), Lei et al. (2011), and REAS 2 are significantly lower than ours, which is based on local measurements. EC emissions from 2005 to 2010 estimated in this work are a little higher than 
our previous work (Y. Zhao et al., 2013), because wood combustion in industry is now included and larger emission factors for small coal and biofuel stoves are used in the current estimate. R. Wang et al. (2012) have the highest EC emission estimates among all the studies, due mainly to the higher emission factors of residential fuels used in that study.

Our estimates of OC emissions are 33-47\% lower than those of $\mathrm{Lu}$ et al. (2011) for different years, and 23-27\% lower than those of Zhang et al. (2009), Lei et al. (2011), and REAS 2, even though they did not include the emissions from biomass open burning, an important OC source that is estimated to contribute $400-600 \mathrm{Gg}$ OC emissions per year according to Lu et al. (2011) and this work. The relatively big gaps between studies come mainly from the highly varied emission factors of residential biofuel combustion used in different inventories. The OC emission factors for biofuel employed by Lu et al. (2011), Zhang et al. (2009), Lei et al. (2011), and REAS 2 are almost twice ours. Those emission factors, however, were largely based on a review by Bond et al. (2004) with a global scope, and were calculated as products of $\mathrm{PM}$ emission factors and mass fractions of carbonaceous species (i.e., $F_{\mathrm{EC}}$ and $F_{\mathrm{OC}}$ ) from laboratory experiments, because no direct measurements of carbonaceous aerosol emission factors for cook stoves were available at that time; for example, $F_{\mathrm{EC}}$ and $F_{\mathrm{OC}}$ for crop wastes burned in cook stoves were estimated at 0.15 and 0.57 , respectively, leading to a ratio of emission factors of OC and EC of 3.8. Nevertheless, the design and combustion conditions of biofuel stoves can differ significantly between China and western countries (personal communication with Y. Chen from Yantai Institute of Coastal Zone Research, Chinese Academy of Sciences, 2014). Measurements of emission factors for biofuel burned in typical Chinese cook stoves have now gradually been conducted (Cao et al., 2008; Li et al., 2009; Shen et al., 2010, 2012, 2013; Wei et al., 2014). Incorporating the results of these local studies, $\mathrm{EF}_{\mathrm{EC}}$ does not differ much but the $\mathrm{EF}_{\mathrm{OC}}$ to $\mathrm{EF}_{\mathrm{EC}}$ ratio for crop waste burning is estimated at 2.2, i.e., $45 \%$ lower than that suggested by Bond et al. (2004). Lower emission factors and thereby emissions of $\mathrm{OC}$ are thus estimated in this work compared to previous studies. Given the complexity of China's residential stoves and possible huge variation of combustion conditions, however, the representativeness and accuracy of existing measurements, and the emission inventories based on those measurements, should continue to be carefully evaluated as more observations on pollution trends of carbonaceous aerosols become available.

\section{Characteristics of carbonaceous aerosols based on observations}

The temporal, spatial, and size distributions of ambient carbonaceous aerosols are analyzed based on available data for China. A database of OC and EC concentrations is com- piled from literature on or including observation of carbonaceous aerosols over a recent 10-year period (2000-2010) in China. "Carbonaceous aerosol concentrations" refers here to those in $\mathrm{PM}_{2.5}$, apart from discussion of size distribution in Sect. 3.4 and where otherwise specifically noted. We need to acknowledge that comparison of OC and EC concentrations in studies using different analytical methods introduces uncertainty, which cannot be simply overlooked. The influence of this uncertainty on the carbonaceous aerosol pattern at national scale is also discussed in the section.

\subsection{Spatial pattern of $\mathrm{OC}$ and EC levels}

To better understand the spatial patterns of carbonaceous aerosol levels, OC and EC concentrations reported in different regions across the country with sufficient sampling periods (at least including both cold and warm seasons) were selected and summarized in Table S4 in the Supplement. Studies with relatively short sampling periods are excluded. Geographical locations of the ground observation sites of the compiled data are illustrated in Fig. S2 in the Supplement. The sites can be classified into different groups: urban/suburban sites located in/near large cities, rural sites that are more representative of regional concentrations, and remote sites that are hardly influenced by human activities and thus representative of background concentrations.

Among the selected studies, the annual means of urban ambient concentrations range from 7.1 to $64.8 \mu \mathrm{g} \mathrm{m}^{-3}$ for OC and 2.2 to $14.3 \mu \mathrm{g} \mathrm{m}^{-3}$ for EC, with an average of 23.9 and 7.5, 17.2 and 5.2, and 20.6 and $6.4 \mu \mathrm{g} \mathrm{m}^{-3}$ for northern, southern, and all cities, respectively. From fewer studies, the averages of OC and EC concentrations for suburban sites are estimated at 16.4 and $4.4 \mu \mathrm{g} \mathrm{m}^{-3}$, respectively, lower than those for urban sites. In general, those values are much higher than those of cities in industrialized Asian countries, North America, and Europe. For example, $5.5 \mu \mathrm{g} \mathrm{m}^{-3}$ for OC and $3.1 \mu \mathrm{g} \mathrm{m}^{-3}$ for EC were observed at Saitama, Japan, during July 2009-April 2010 (Kim et al., 2011); $2.7 \mu \mathrm{g} \mathrm{m}^{-3}$ for OC and $1.1 \mu \mathrm{g} \mathrm{m}^{-3}$ for EC at New York City during February 2000-December 2003 (Qin et al., 2006); and $3.8 \mu \mathrm{g} \mathrm{m}^{-3}$ for OC and $3.8 \mu \mathrm{g} \mathrm{m}^{-3}$ for EC at Madrid during June 2009-February 2010 (Pio et al., 2011). Particularly high concentrations were found in Xi' an $\left(64.8 \mu \mathrm{g} \mathrm{m}^{-3}\right.$ for OC and $14.3 \mu \mathrm{g} \mathrm{m}^{-3}$ for EC in 2003) and Chongqing (50.9 $\mu \mathrm{g} \mathrm{m}^{-3}$ for OC and $12.3 \mu \mathrm{g} \mathrm{m}^{-3}$ for EC in 2003), due probably to the combined contribution of coal combustion emissions and unfavorable meteorological conditions (Cao et al., 2007). However, the average carbonaceous concentrations measured by Chen et al. (2014) during May 2012April 2013 in Chongqing $\left(19 \mu \mathrm{g} \mathrm{m}^{-3}\right.$ for OC and $4.6 \mu \mathrm{g} \mathrm{m}^{-3}$ for EC) were significantly lower than those measured by Cao et al. (2007) in 2003, presumably due to improved implementation of emission control policies. Compared with $\mathrm{Xi}$ 'an, the relatively lower concentrations of carbonaceous aerosols in developed cities in the North China Plain (NCP) 
including Beijing, Tianjin, and Qingdao might result from a widespread switch from coal and biofuel to natural gas in residential use (Ge et al., 2004). As reported by P. Zhao et al. (2013), Beijing, Tianjin, Shijiazhuang, and Chengde have almost the same levels of OC and EC concentrations with ratios of observed OC to EC (OC / EC) of around 2.7, implying similar sources of carbonaceous aerosols and/or regional meteorological conditions.

The concentrations of carbonaceous aerosols in China overall show a pattern with higher levels found in northern and inland cities while lower levels in southern and coastal ones, consistent with what Cao et al. (2007) investigated in 14 cities. This pattern, however, might be influenced by uncertainty from different sampling and analytical methods used in selected observations. For example, the uncertainty from measurement methods and thermal-optical temperature protocols on the OC to EC ratio reached 10-40\% in Beijing (Cheng et al., 2011, 2014). As most studies did not compare the results from different measurement methods, it is difficult to directly estimate the uncertainty at the national scale. To evaluate the influence of measurement uncertainty, the average concentrations for northern and southern cities are recalculated for the 43 out of 59 urban observation studies applying the IMPROVE_TOR (Thermal-optical reflectance with the Interagency Monitoring of Protected Visual Environments protocol) method, the most frequently applied method across the country. As shown in Table S4, the result with higher concentrations in northern cities still holds, indicating the pattern at the national scale would not be significantly influenced by the uncertainty from measurement methods. The difference between northern and southern China results partly from (1) the larger emission intensity of primary carbonaceous aerosols in the north as described in Sect. 2.3, particularly in the heating seasons due to enhanced use of coal and biofuel in the residential sector (Lu et al., 2010); and (2) relatively favorable meteorological conditions including more frequent precipitation and less temperature inversion in the south. The effects of monsoonal rainfall could also be a reason for lower concentrations in coastal cities than inland ones.

The annual average OC and EC concentrations at rural stations range from $4.2-37.7 \mu \mathrm{g} \mathrm{m}^{-3}$ to $0.7-4.9 \mu \mathrm{g} \mathrm{m}^{-3}$, with the overall average concentrations at 12.2 and $2.5 \mu \mathrm{g} \mathrm{m}^{-3}$, respectively. Most observed OC concentrations are below $16 \mu \mathrm{g} \mathrm{m}^{-3}$ except for Jinan, a city impacted by intensive coal use. All EC concentrations are below $5 \mu \mathrm{g} \mathrm{m}^{-3}$ and much smaller than those at the urban/suburban sites. As with the urban sites, the carbonaceous aerosol levels at rural sites are generally higher than those in other parts of the world, e.g., $1.6 \mu \mathrm{g} \mathrm{m}^{-3}$ of OC and $0.61 \mu \mathrm{g} \mathrm{m}^{-3}$ of EC at Egbert in Canada, during August 2005-November 2007 (Yang et al., 2011b), $3.8 \mu \mathrm{g} \mathrm{m}^{-3}$ of OC and $1.3 \mu \mathrm{g} \mathrm{m}^{-3}$ of EC at Cape Fuguei, Taiwan, during 2003-2007 (Chou et al., 2010), and $3.2 \mu \mathrm{g} \mathrm{m}^{-3}$ of OC and $0.9 \mu \mathrm{g} \mathrm{m}^{-3}$ of EC at West Midlands,

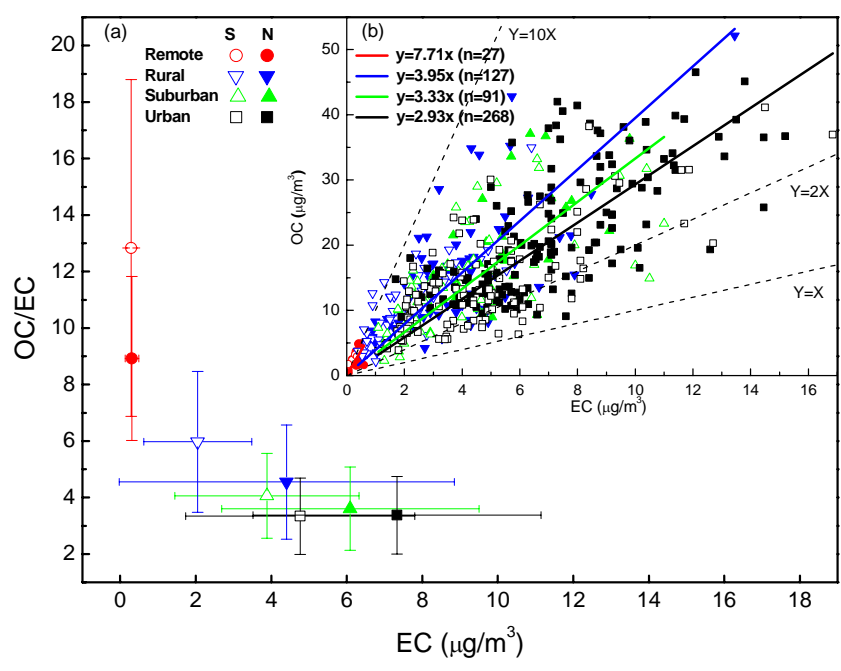

Figure 4. (a) Averaged ambient OC / EC ratios versus EC concentrations in $\mathrm{PM}_{2.5}$ with standard deviations from seasonal observation data at southern $(\mathrm{S}$; open symbols) and northern $(\mathrm{N}$; solid symbols) remote, rural, suburban, and urban sites in China; and (b) regressions of observed seasonal means of OC and EC concentrations in $\mathrm{PM}_{2.5}$ for remote, rural, suburban, and urban sites in China. The lines indicating $\mathrm{OC} / \mathrm{EC}=1(Y=X), 2(Y=2 X)$, and $10(Y=10 X)$ are plotted for comparison.

UK, during November 2005-May 2006 (Harrison and Yin, 2008).

The annual OC and EC concentrations at remote sites range from 0.5 to 5.8 and 0.06 to $0.8 \mu \mathrm{g} \mathrm{m}^{-3}$, respectively, much lower than those in urban, suburban, and rural sites, as expected. The background concentrations are comparable to the levels at Sonnblick in the Austrian Alps, at $0.81 \mu \mathrm{g} \mathrm{m}^{-3}$ of OC and $0.07 \mu \mathrm{g} \mathrm{m}^{-3}$ of EC during OctoberDecember 2002 and May-June 2003 (Gelencsér et al., 2007).

\subsection{OC / EC and SOC formation levels across the country}

As noted above, ambient OC is composed of POC emitted directly and SOC formed by chemical reactions in the atmosphere. In general, an OC / EC ratio exceeding a threshold of 2.0 is used to indicate the presence of secondary organic aerosols (Turpin and Lim, 2001). As shown in Table S4, most of the annual mean OC / EC ratios are equal to or above 2.0, implying the prevalence of SOC across the country. In addition to annual averages, $\mathrm{OC}$ and $\mathrm{EC}$ concentrations in $\mathrm{PM}_{2.5}$, $\mathrm{PM}_{10}$, or total suspended particles (TSP) observed for relatively short sampling periods (i.e., to be seasonally representative) from available studies in the country are compiled and included in the OC / EC analysis. As shown in Fig. S3 in the Supplement, the distribution, in total, of the 513 data points in sampling year and season does not differ much between the south and north, implying limited bias from sampling time on the spatial pattern of OC/EC. Illustrated in 
Fig. 4a are the averages of OC / EC ratios versus EC concentrations with standard deviations at southern ( $\mathrm{S}$; open symbols) and northern (N; solid symbols) remote, rural, suburban, and urban sites in China. In most cases, ambient EC concentrations in the north are higher than those in the south, but larger OC / EC ratios are found in the south for remote and rural sites. The result is consistent with the spatial pattern of provincial emissions shown in Fig. 2c, with the annual means of $(\mathrm{OC} / \mathrm{EC})_{\mathrm{emi}}$ calculated at 1.67 and 1.45 for southern and northern China, respectively, during 2000-2012. Besides primary emissions, differences in the conditions for SOC formation contribute as well to the divergent ambient OC / EC ratios in the south and north, which will be discussed later in this section. While EC levels indicating pollution from primary emissions are higher at urban sites, larger ambient OC / EC ratios are found for remote and rural sites. As shown in Fig. 4b, regression analyses are conducted for seasonal OC and EC concentrations classified by functional zone (i.e., urban, suburban, rural and remote regions). Ratios of OC / EC are larger than 1.0 for all data points, and a clear difference in $\mathrm{OC} / \mathrm{EC}$ is found by functional zone, with the regression slopes of seasonal mean concentrations at 2.93 for urban, 3.33 for suburban, 3.95 for rural, and 7.71 for remote sites. To examine the influence of analytical method, the studies with IMPROVE_TOR and NIOSH_TOT (Thermaloptical transmission method with National Institute of Occupational Safety and Health protocol) method (number of data points: 292 and 160, respectively) are re-evaluated. As shown in Figs. S4 and S5 in the Supplement, similar pattern of OC / EC in the north and south and gradients of OC / EC between functional zones can be found (as seen in Fig. 4). We should note, however, that uncertainty exists in the comparison. Since current available campaigns using a certain analytical method for a given type of site (particularly for remote site) are still insufficient, the results can be easily influenced by limited studies, as indicated by relatively big standard deviations in Figs. 4a, S4a, and S5a. To better understand the OC / EC pattern at national scale, therefore, more campaigns for varied locations, particularly at remote sites, are recommended.

The variation in OC / EC ratios by functional zone results from the joint effects of local emission characteristics and regional formation and transport of SOC. Watson et al. (2001) estimated average ratios of primary $\mathrm{OC}$ to $\mathrm{EC}$ emissions for vehicles, coal combustion, and biomass burning at 1.1, 2.7, and 9.0, respectively. For urban areas of economically advanced cities in the JJJ and YRD regions, vehicles make a greater contribution to total carbonaceous emissions compare to rural or developing regions, leading to smaller observed OC / EC. In current inventory as described in Section 2, for example, transportation is estimated to account for $37 \%$ of total EC emissions in the YRD provinces (Shanghai, Jiangsu, and Zhejiang) for 2012, much larger than the national average level at $17 \%$. As can be seen in Fig. 4b, most of the seasonal OC / EC ratios lower than 2 (below the $Y=2 X$ line) were observed at urban sites. In rural areas, biomass combustion (with larger primary OC / EC emission ratio) contributes more than it does in urban areas, and the regional contribution of aged aerosols with higher SOC levels helps to elevate the ambient OC / EC. Similarly, the highest OC / EC are found for the remote or high mountain areas, attributed to the following: (1) those sites are far from anthropogenic sources, especially those with relatively high emissions of EC (e.g., vehicles); (2) the formation and regional transport of SOC has increased the contribution to OC levels compared to urban areas; (3) the influence of natural sources is significantly higher at remote sites, with enhanced production of OC but very little EC; and (4) semi-volatile organic compounds tend to be condensed to particle $\mathrm{OC}$ in high mountain areas due to the low temperature.

It must be noted that the observed OC / EC is not sufficient to support comprehensive source apportionment of carbonaceous aerosols, which remains unclear in China. Through various methods, transportation is identified as an important source of carbonaceous aerosols in developed cities although the results differ and depend largely on region, period, and the method used; for example, the contribution of transportation to OC in winter in Beijing could exceed $70 \%$ with a simple ratio method (Zhang et al., 2007). The contribution of transportation to TC was estimated to range $47-96 \%$ in autumn and winter in urban Xi' an, with principle component analysis method (Cao et al., 2005a). Using chemical mass balance method, biomass burning and transportation were estimated to be the most important source of OC in Hong Kong (Y. C. Li et al., 2012; Hu et al., 2010), while transportation could contribute $30 \%$ of excess OC for the PRD region compared to Hong Kong (Zheng et al., 2011). Studies using isotopic tracer method indicated less contribution of biomass burning but more from fossil fuel in developed urban regions compared to rural and developing ones (Huang et al., 2010; Niu et al., 2013).

Lacking any direct analytical techniques to quantify POC or SOC concentrations, several indirect methods have been used to estimate the latter. One of the most used is the EC-tracer method due to its simplicity and data availability. The concentrations of POC and SOC can be calculated with Eqs. (3) and (4):

$\mathrm{POC}=(\mathrm{OC} / \mathrm{EC})_{\mathrm{pri}} \times \mathrm{EC}+\mathrm{OC}_{\mathrm{nc}}$,

$\mathrm{SOC}=\mathrm{OC}_{\mathrm{tot}}-\mathrm{POC}$,

where $\mathrm{OC}_{\text {tot }}$ and $\mathrm{EC}$ are the observed total $\mathrm{OC}$ and $\mathrm{EC}$ concentrations, respectively; (OC / EC) pri is the ratio of primary $\mathrm{OC}$ and EC emissions with the contribution of SOC excluded (Castro et al., 1999); and $\mathrm{OC}_{\mathrm{nc}}$ is the $\mathrm{OC}$ emissions from non-combustion sources and it is usually small and sometimes overlooked in the calculation.

As the crucial parameter in the approach, $(\mathrm{OC} / \mathrm{EC})_{\text {pri }}$ can be determined in various ways, including the $\mathrm{OC}$ to $\mathrm{EC}$ ratio from emission inventory (i.e., $(\mathrm{OC} / \mathrm{EC})_{\mathrm{emi}}$ ), OC to EC 


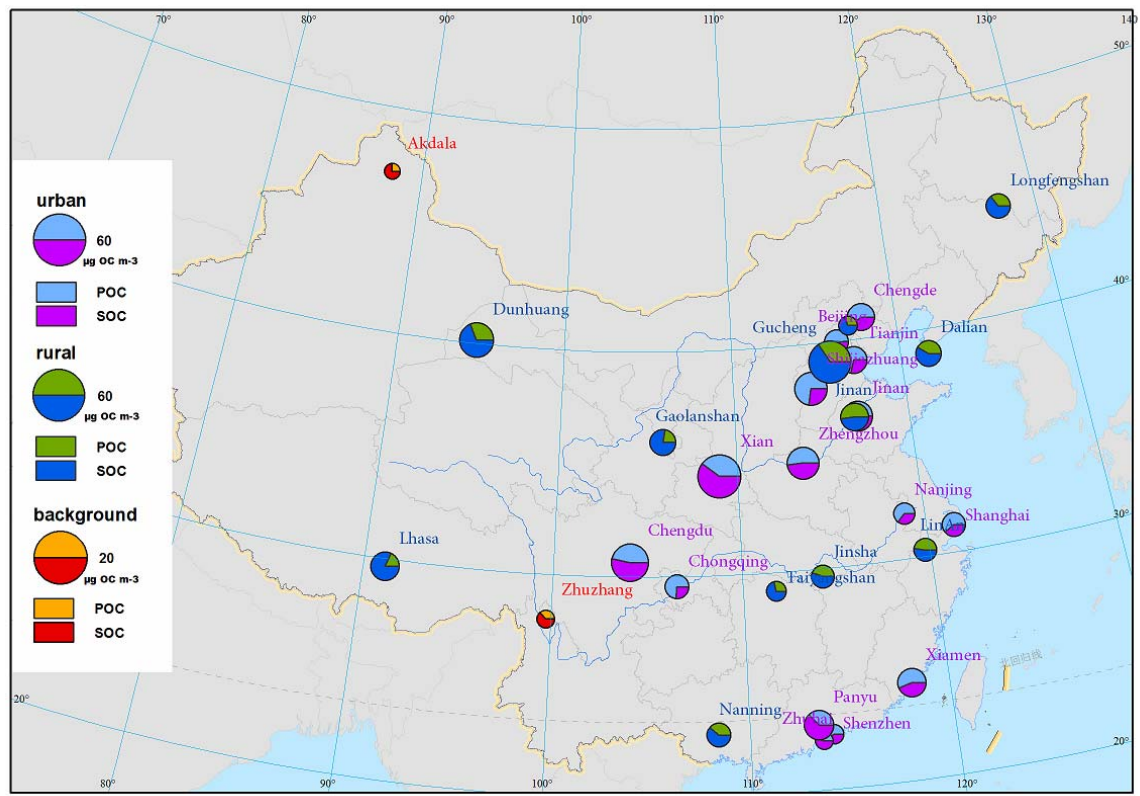

Figure 5. Annual averages of OC concentrations and mass fractions of POC and SOC to OC by region from various studies, including (1) urban sites: Beijing (Lin et al., 2009); Tianjin, Shijiazhuang, and Chengde (P. Zhao et al., 2013); Jinan (Yang et al., 2012); Guangzhou (Duan et al., 2007); Xiamen (Zhang et al., 2011); Shenzhen and Zhuhai (Cao et al., 2003a, 2004); Shanghai (Feng et al., 2009); Nanjing (Wu et al., 2013); Chongqing (Chen et al., 2014); Chengdu, Panyu, Xi'an, Zhengzhou, Nanning, and Dalian (X. Zhang et al., 2008); (2) rural sites: Jinan (Yang et al., 2012); Gucheng, Taiyangshan, Longfengshan, Dunhuang, Linan, Jinsha, Lhasa, Gaolanshan, and Shangdianzi (X. Zhang et al., 2008); and (3) remote sites: Akdala and Zhuzhang (Qu et al., 2009). SOC concentrations were obtained by original studies using the EC-tracing method (Eqs. 3 and 4; Castro et al., 1999). The minimum or the lowest 5-20\% OC / EC ratios were used as the (OC / EC) pri (Cao et al., 2007). Note the scales of pie charts indicating OC concentrations are not uniform for urban, rural, and remote sites, to ease visualization.

concentration ratio from observation when SOC formation is weak and thus the concentrations are dominated by emissions, or the lowest $\mathrm{OC}$ to EC concentration ratio during the observation. In this work, we make a comprehensive review of available observation campaign studies that reported POC and SOC in different regions across the country. The mass fractions of POC and SOC, estimated by original individual studies, are collected and summarized in Fig. 5. For urban JJJ and YRD regions, a POC is the main fraction of OC, indicating a large contribution of primary anthropogenic emissions. In contrast, higher mass fractions of SOC to OC are found in other cities, particularly those in southern China, due mainly to the favorable condition for SOC formation such as relatively high temperature and sufficient sunlight. For all sites, SOC / OC at the remote and rural sites is generally greater than those at urban sites. It thus confirms the formation and transport of SOC at a regional scale, and could partly explain the discrepancies in $\mathrm{OC} / \mathrm{EC}$ by region.

As a semi-quantitative method, the EC-tracer method has limitations: the determination of (OC / EC) $)_{\text {pri }}$ is arbitrary and unable to obtain a single $\mathrm{OC} / \mathrm{EC}$ ratio that represented a mixture of primary sources varying in time and space (Yuan et al., 2006). For example, overestimate of SOC can be made during the period of biomass open burning with a very high emission ratio of OC to EC (Ding et al., 2012). Although occasional irregular contributions from sources with a primary $\mathrm{OC}$ to EC ratio vastly different from the usual mix of sources could cause errors in estimated SOC, the ECtracer method, as the most widely applied approach across the country, is believed to provide a reasonable SOC level at monthly or seasonal average when high-frequency measurements are conducted (Folidori et al., 2006). Improvement has been made on the approach by recent studies. Chen et al. (2014) combined the EC-tracer method and potassium mass balance to reduce the impacts of biomass burning on SOC calculation. Day et al. (2015) modified the criterion of $(\mathrm{OC} / \mathrm{EC})_{\text {pri }}$ by choosing EC / OC points that are 2 standard deviations above the mean value, and demonstrated a better performance of SOC estimation by comparing the results with those from chemical transport model. Hu et al. (2012) modified the method by varying (OC / EC) pri within a defensible range to obtain a series of $R^{2}$ correlation coefficients between SOC and EC. The best (OC / EC) pri can then be determined as the one corresponding to the minimum $\mathrm{R}^{2}$, or when SOC is least correlated with EC. The (OC / EC) $)_{\text {pri }}$ from the improved method showed strong agreement with the regression slope of OC to EC in the days when the pollution was mainly influenced by local emissions, indicating that the 
errors from the subjectively determined OC / EC threshold can be partly reduced (Hu et al., 2012).

\subsection{Seasonal variation of carbonaceous aerosol species}

Seasonal variations of ambient carbonaceous aerosol levels are illustrated by region in Fig. 6. For ease of visualization, concentrations of OC, EC, and SOC for each season are normalized by dividing by the maximum seasonal concentrations, while OC / EC and SOC / OC are normalized by dividing by the maximum seasonal ratios.

For both urban and rural sites, OC and EC concentrations were generally higher in winter and lower in summer, with some exceptions. For instance, the highest concentrations were found in autumn for Shanghai, probably due to the proximity of biomass combustion (Feng et al., 2009). In most cases, EC has the same seasonal pattern as OC, indicating they are of common origin and/or influenced by the same meteorological factors. On the one hand, enhanced emissions (particularly in northern China) combined with a stagnant atmosphere favor accumulation in winter and result in an increase of carbonaceous aerosol concentrations. On the other hand, the higher mixed layer and increased monsoonal precipitation in summer lead to stronger dispersion and deposition of aerosols. Similar to OC and EC, OC / EC is generally higher in spring and winter, whereas the seasonal variations in OC / EC at southern urban sites are relatively small compared to those at northern sites, reflecting less difference in emissions between cold and warm seasons in the south. Consistent seasonal patterns are found between OC / EC and carbonaceous aerosol concentrations at northern urban sites, while some inconsistencies, such as enhanced OC/EC in summer, occur in the south. It thus implies that the meteorology that favors SOC generation may play a more important role in the seasonal pattern of ambient carbonaceous aerosol levels and their ratios in the south.

As a component of OC, SOC concentrations are generally higher in autumn and winter except for Beijing (Lin et al., 2009) and Akdala (Qu et al., 2009), and similar seasonal variations are found for urban and rural sites. Despite the presence of more photochemical oxidants and VOC emissions in summer, the highest SOC concentrations were observed in winter for most cities. The SOC level in winter in Shijiazhuang, for example, was notably 8 times higher than that in summer (P. Zhao et al., 2013). This result, however, might be biased when biomass open burning prevails in winter, as the EC-tracer method could possibly be mistaken as part of primary OC from biomass burning as SOC and thereby to result in overestimation in SOC (Ding et al., 2012; Feng et al., 2013). The stagnant conditions and low temperatures that facilitate the accumulation of air pollutants and favor partitioning of oxidation products into the particle phase could be the reason for the high SOC in cold seasons (Folidori et al., 2006; P. Zhao et al., 2013). Using a smog chamber experiment, Huang et al. (2014) confirmed that low temperature does not significantly reduce $\mathrm{SOC}$ formation rates from emissions of biomass burning, and large amounts of SOC could be rapidly produced, exceeding POC. During the severe haze event in Jan 2013, high levels of organic aerosols were found to be largely driven by SOC formation, estimated to be responsible for $44-71 \%$ of total OC in four big cities across China (Huang et al., 2014).

A larger contribution of SOC to OC (SOC / OC) is found in autumn and winter for most sites, while its seasonal variations are generally smaller compared to those of SOC concentrations, particularly for rural, remote, and southern urban sites. The highest SOC / OC ratios were in fact found in summer at some urban sites including Beijing (Lin et al., 2009), Nanjing (Wu et al., 2013; Li et al., 2015), and Tianjin (Gu et al., 2010; not plotted in Fig. 6), and rural or remote sites such as Longfengshan, Taiyangshan, and Akdala (X. Zhang et al., 2008, 2012). Although the absolute SOC levels are higher in winter, the oxidation reactions from VOCs to OC are implied to be faster in summer because of higher temperature and more abundant VOC precursors, accelerating SOC formation and thus elevating SOC / OC.

\subsection{Distribution of carbonaceous species by particle size}

The relationships of ambient OC, EC, and the OC / EC ratio to different particle sizes are given in Table 3. From available observations, the OC and EC mass fractions of fine particles $\left(\mathrm{PM}_{2.5}\right)(8.6-25.5 \%$ and $3.5-11.7 \%$, respectively) are larger than those of $\mathrm{PM}_{10}(4.0-20.0$ and $2.8-8.3 \%)$. The OC and EC mass in $\mathrm{PM}_{2.5}$ respectively accounts for $51.8-86.4 \%$ and $56.7-90.9 \%$ of that in $\mathrm{PM}_{10}$, greater than the mass fractions of $\mathrm{PM}_{2.5}$ to $\mathrm{PM}_{10}$ (43.0-74.4\%). This information clearly confirms that ambient OC and EC are not uniformly distributed in particles but enriched in the fine particle fraction. Larger OC / EC ratios, however, are found in $\mathrm{PM}_{10}$ rather than in $\mathrm{PM}_{2.5}$ in most cases. Such differing distributions of OC and EC reflect the different sources of carbonaceous aerosols in the atmosphere (G. Wang et al., 2010). EC is usually associated with incomplete combustion, which releases into the atmosphere carbonaceous matter mainly in the form of submicron particles. Also enriched in fine particles, OC is nevertheless distributed over a wider range of particle sizes, because condensation processes in the atmosphere can also generate OC. In addition, particles of biogenic origin, including plant debris, pollen, and fungal spores, can accumulate in the coarse particle fraction (Matthias-Maser and Jaenicke, 2000). Therefore, the smaller OC / $\mathrm{EC}$ ratios in $\mathrm{PM}_{2.5}$ imply a greater importance of anthropogenic sources to fine particles. The results in China are consistent with European studies, in which OC / EC in cities was higher in larger particles (Pio et al., 2011). 

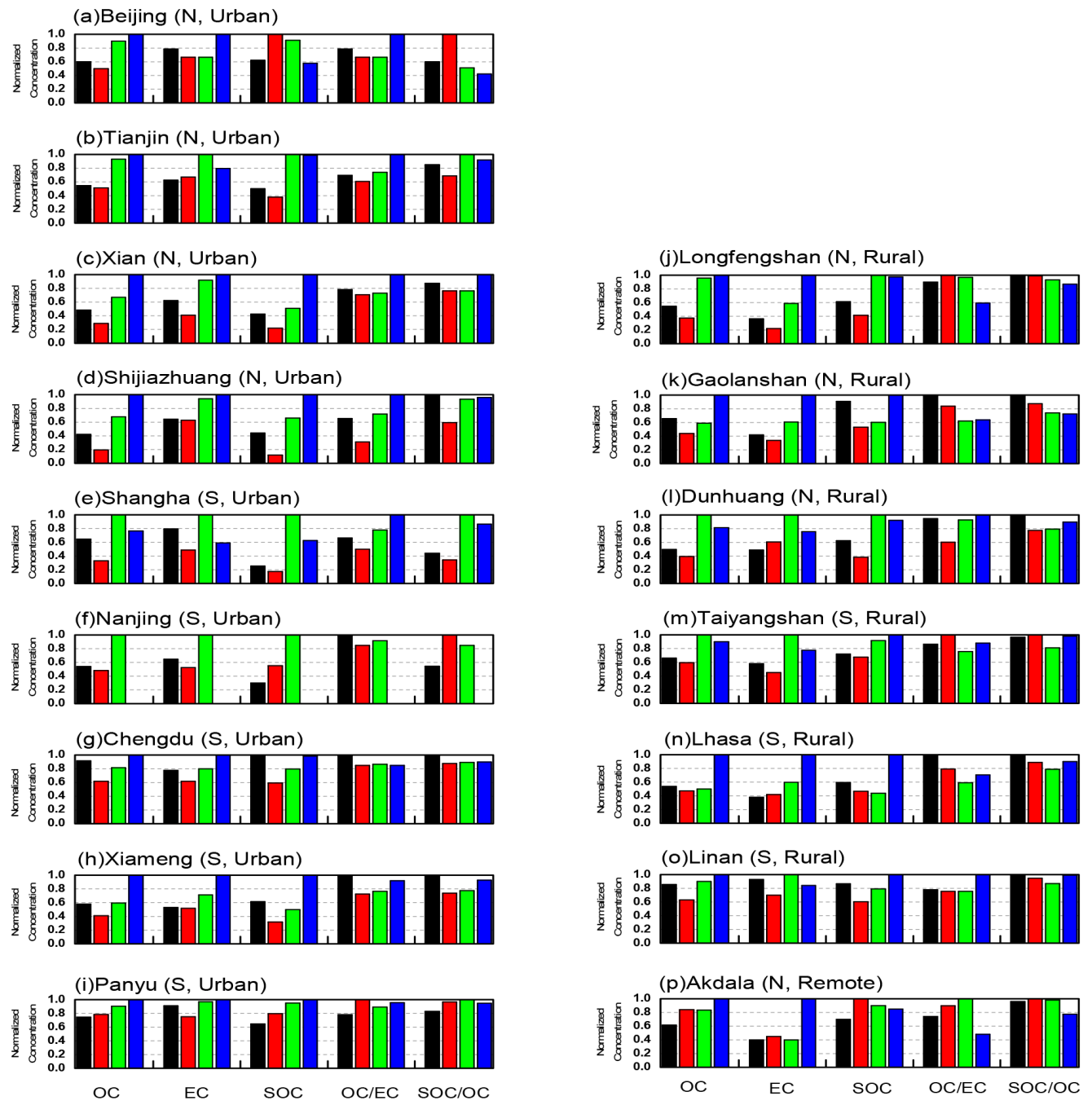

Wpring $\square$ Summer $\square$ Autumn $\square$ Winter

Figure 6. Seasonal variation of normalized OC, EC, SOC, OC / EC and SOC / OC in $\mathrm{PM}_{2.5}$ (Beijing, Tianjin, Shijiazhuang, Shanghai, Nanjing, and Xiamen) or $\mathrm{PM}_{10}$ (other cities) by region from various studies, including (1) urban sites: Beijing (Lin et al., 2009); Tianjin and Shijiazhuang (P. Zhao et al., 2013); Shanghai (Feng et al., 2009); Nanjing (Li et al., 2015); Xiamen (F. Zhang et al., 2012); Xi' an, Chengdu, and Panyu (X. Zhang et al., 2008, 2012); and (2) rural/remote sites: Longfengshan, Gaolanshan, Dunhuang, Taiyangshan, Lhasa, and Linan (X. Zhang et al., 2008, 2012); Akdala (Qu et al., 2009). N and S represent northern and southern sites, respectively.

\subsection{Characteristics of carbonaceous aerosols for typical periods}

In addition to research focused on annual or seasonal averages, studies have been conducted on carbonaceous aerosol levels during high-pollution, clear, and other typical event periods. For example, at a rural site in the PRD in summer of 2006, the average OC and EC concentrations observed during days of strong influence of local emissions or of typhoons and high precipitation compared to normal days (Hu et al., 2012). Clear distinctions in pollution levels were found between periods: $28.1 \mu \mathrm{g} \mathrm{m}^{-3}$ of OC and $11.6 \mu \mathrm{g} \mathrm{m}^{-3}$ of EC during days of strong local emission influence, $4.0 \mu \mathrm{g} \mathrm{m}^{-3}$ of $\mathrm{OC}$ and $1.8 \mu \mathrm{g} \mathrm{m}^{-3}$ of EC during those influenced by typhoons or high precipitation, and $5.7 \mu \mathrm{g} \mathrm{m}^{-3}$ of $\mathrm{OC}$ and $3.3 \mu \mathrm{g} \mathrm{m}^{-3}$ of EC for normal days. Relatively low concentrations of carbonaceous aerosols were observed during the campaigns of the Beijing Olympics in 2008 (X. Li et al., 2012), Shanghai World Expo in 2010 (Wang et al., 2014), and Nanjing Asian Youth Games in 2013 (Yu et al., 2014), showing the effectiveness of pollution control measures on air quality for those events.

More studies have focused on heavy pollution periods, such as hazy days and biomass-burning seasons. A hazy day 


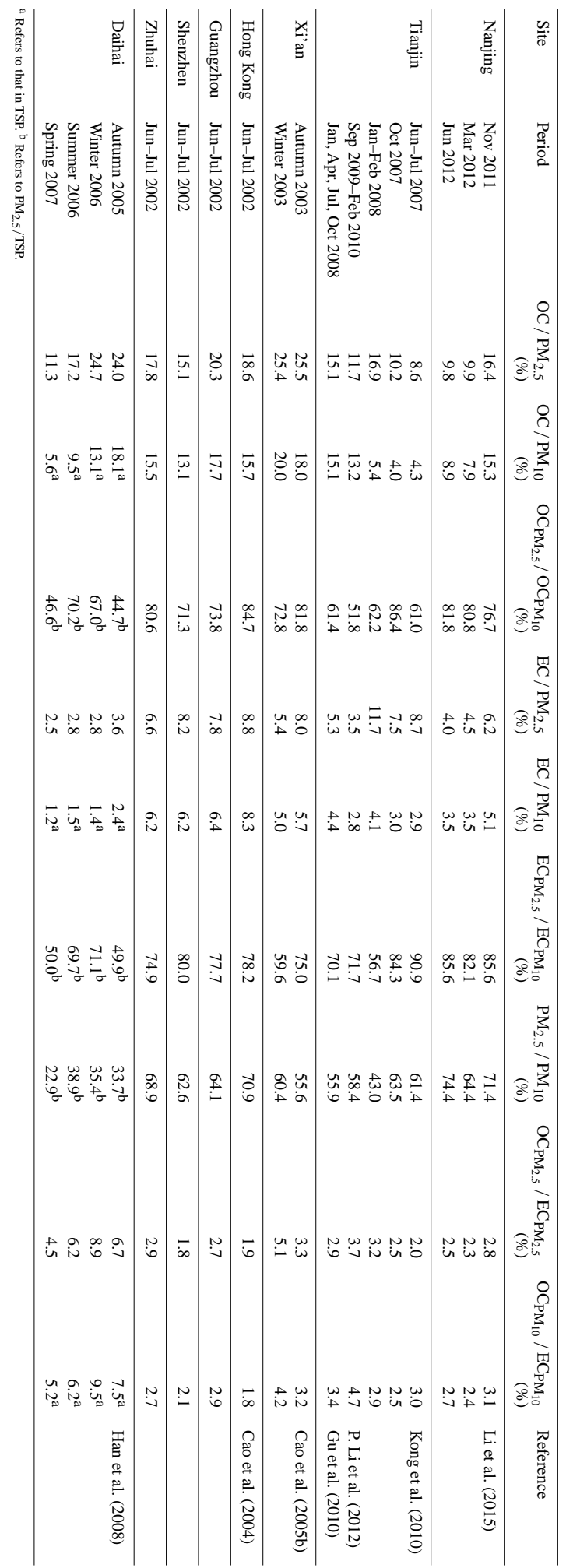

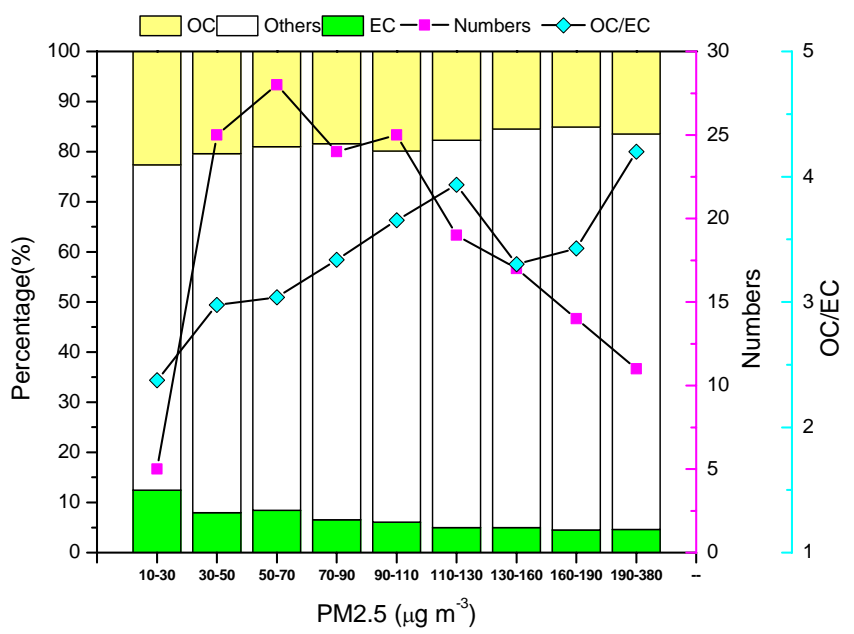

Figure 7. The carbonaceous aerosol mass fractions of ambient $\mathrm{PM}_{2.5}$ and $\mathrm{OC} / \mathrm{EC}$ ratios, classified by $\mathrm{PM}_{2.5}$ concentration from reconstructed data measured in areas highly affected by anthropogenic sources (i.e., urban and suburban sites) in China. Numbers of data points by $\mathrm{PM}_{2.5}$ level are also shown.

is defined by daily average atmospheric visibility less than $10 \mathrm{~km}$ (Hou et al., 2011), with $\mathrm{PM}_{2.5}$ one of the most important contributors. In this work, the seasonal averages of $\mathrm{PM}_{2.5}$ concentrations in urban or suburban sites throughout China during 2000-2010 are compiled based on available studies, and an approximate lognormal distribution is derived for frequency of $\mathrm{PM}_{2.5}$ levels with a data sample size of 170, as shown in Fig. 7. Around $60 \%$ of the $\mathrm{PM}_{2.5}$ values exceeded the national standard of $75 \mu \mathrm{g} \mathrm{m}^{-3}$, reflecting heavy pollution throughout the country. Compared with clear periods, for example, carbonaceous aerosols as well as other components in $\mathrm{PM}_{2.5}$ were greatly enhanced during local haze periods, by up to $430 \%$ in Guangzhou (Jung et al., 2009) and about 160, 170, and $180 \%$ for OC, EC and secondary non-organic aerosols (SNA), respectively, in Fuzhou (F. Zhang et al., 2013). As shown in Fig. 7, moreover, larger mass fractions of carbonaceous aerosols in $\mathrm{PM}_{2.5}$ are found for periods with relatively lower $\mathrm{PM}_{2.5}$ levels, and the fractions of $\mathrm{OC}$ and EC to $\mathrm{PM}_{2.5}$ were 27 and $63 \%$ less, respectively, at $\mathrm{PM}_{2.5}$ concentrations of $190-380 \mu \mathrm{g} \mathrm{m}^{-3}$ compared to those of $10-30 \mu \mathrm{g} \mathrm{m}^{-3}$. The results indicate, on one hand, that rapid increase in other compounds like SNA contributes significantly to heavy haze events. For example, in Beijing, the fraction of particles composed of inorganic ions $\left(\mathrm{SO}_{4}^{2-}+\mathrm{NO}_{3}^{-}+\mathrm{NH}_{4}^{+}\right)$increased as $\mathrm{PM}_{2.5}$ levels rose during 1999-2010 (data provided by K. He of Tsinghua University, 2012). On the other hand, the sharp increase in OC / EC along with enhanced $\mathrm{PM}_{2.5}$ levels indicates a significant contribution of SOC to strong haze events. For example, Huang et al. (2011) found that hazy episodes in Harbin were closely related to the high concentrations of $\mathrm{OC}$ and $\mathrm{EC}$, and the av- 
erage OC / EC ratio on hazy days (42.2) was almost 3 times of that in non-haze days (14.5).

Biomass burning is another source with significant impact on ambient aerosol levels and air quality. Elevated levels of carbonaceous aerosols were usually found during the harvest season. For example, OC and EC were observed to increase by 99 and $105 \%$, respectively, during the biomass-burning versus non-biomass-burning periods in Guangzhou (Zhang et al., 2010), and the analogous values for Chengdu were observed to be 148 and $51 \%$ (Wang et al., 2013). With other methods combined, the biomass-burning share of carbonaceous aerosol enhancement has also been quantified in recent studies. Li et al. (2015), using regression analysis of particle $\mathrm{OC}$ and $\mathrm{K}^{+}$of biomass-burning origin, estimated that biomass burning contributed more than half of ambient OC during the harvest season in Nanjing. Based on observations and chemical transport modeling, Cheng et al. (2014) estimated that open biomass burning contributed $37 \%$ of $\mathrm{PM}_{2.5}$, $70 \%$ of OC, and $61 \%$ of EC at five representative cities in the YRD region during May and June, and that a complete ban of biomass burning would reduce the human exposure level of $\mathrm{PM}_{2.5}$ in the region $47 \%$.

\section{Assessment of emission inventories using observations}

\subsection{Comparisons of inter-annual trends in ambient levels and emissions for 2000-2010}

The seasonal means of $\mathrm{OC}, \mathrm{EC}$, and $\mathrm{PM}_{2.5}$ concentrations and the ratios of OC to EC based on available observations are plotted from 2000 to 2010 in Fig. 8, to reflect the trends of carbonaceous aerosols at the national scale. Although an increasing inter-annual trend is found for estimated OC and EC emissions over the 10 years, the observed concentrations of carbonaceous aerosols did not likewise increase, and observed EC actually declined. On the one hand, the improvement of fuel combustion technologies in the residential sector and thereby the possible changes in emission factors cannot be fully captured in current emission inventory studies because of insufficient data on key parameters. This may result in overestimated growth of emissions than that indicated by observed concentrations. Databases of evolving emission factors over time reflecting incremental emission control, particularly in residential combustion sources, are necessary to improve understanding of long-term emission trends in China. On the other hand, the ambient levels of carbonaceous aerosols could also be influenced by changes in meteorological factors in air quality, including wind velocity, humidity, temperature, and stability of the atmosphere (J. Wang et al., 2012). For example, divergent trends in local meteorology for the JJJ and PRD regions led to opposite trends in carbonaceous aerosol levels for the two regions (increased in JJJ but decreased in PRD) in recent years (X. Zhang et al., 2013).
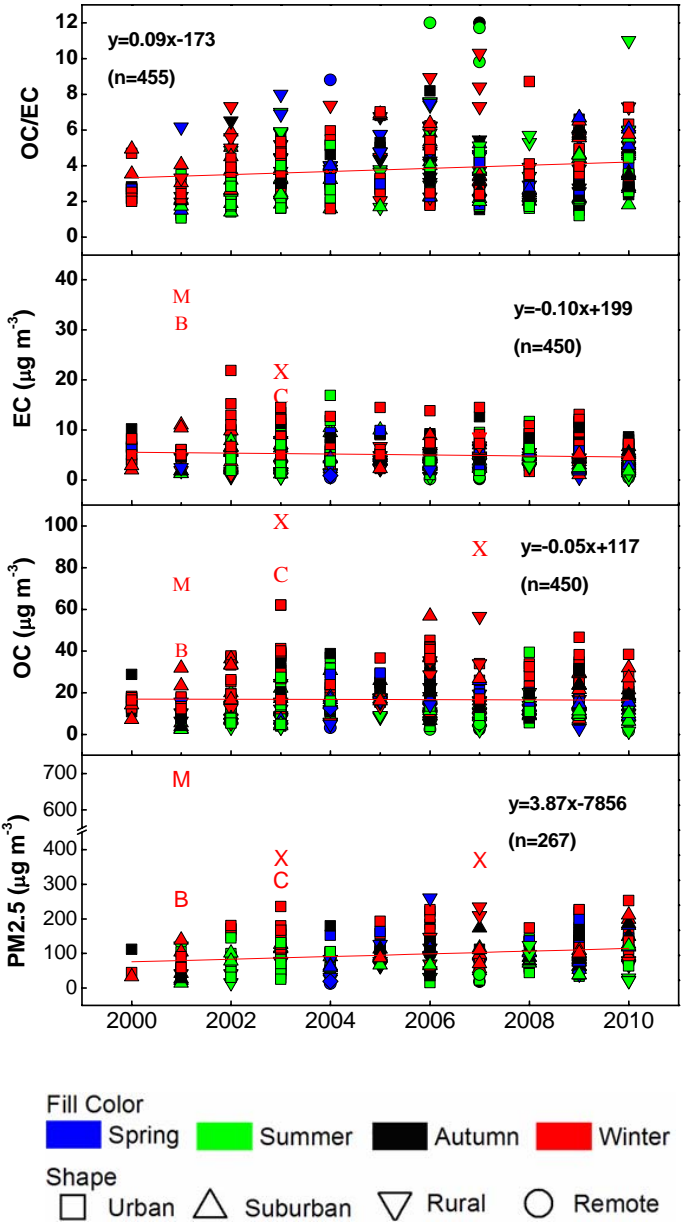

Figure 8. Inter-annual trends of concentrations of OC, EC and $\mathrm{PM}_{2.5}$, and ratios of OC to EC from 2000 to 2010 based on ground observations from various studies. Five data points (B: Beijing; M: Miyun; X: Xi'an; C: Chongqing) are excluded from the linear regression analysis due to the extremely high concentrations observed during heavy haze pollution events.

The estimates of emissions by region should thus be improved to incorporate detailed information on local sources, to carefully differentiate the impacts of emissions and meteorology on carbonaceous aerosol pollution at regional and local scales.

Observations indicate increased OC / EC ratios from 2000 to 2010 at the national scale (Fig. 8), but emission inventories indicate slightly reduced ratios (from 1.58 in 2000 to 1.48 in 2010, as shown in Fig. 2c). This inconsistency might result from (1) the possible underestimation of emissions from sources with significant primary OC, e.g., biomass burning (described later in Sect. 4.2); (2) enhanced SOC formation from increasing VOC emissions (Bo et al., 2008; Wei, 2009) and elevated atmospheric oxidation; and (3) the uncertainty from different methods in OC / EC measurement. For comparison, primary $\mathrm{PM}_{2.5}$ emissions are estimated to have declined after 2005, due to the improved energy structure and 


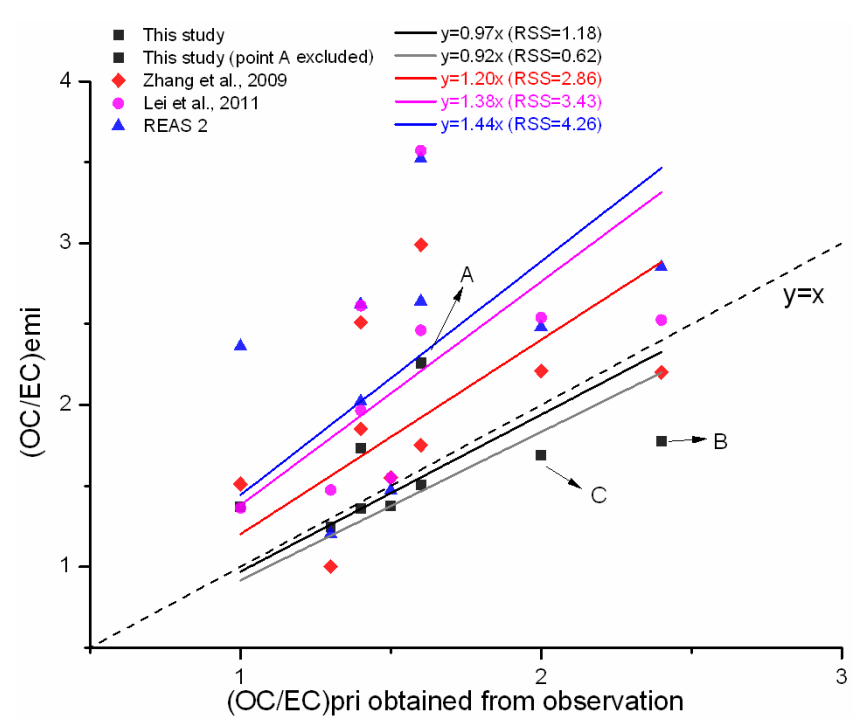

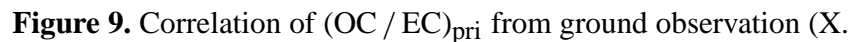
Zhang et al., 2008) and (OC / EC) $)_{\mathrm{emi}}$ from provincial emissions estimated by different inventory studies. Points A, B, and C represent the observations at Nanning, Longfengshan, and Jinsha, and emission results for corresponding provinces (Guangxi, Heilongjiang, and Hubei), respectively.

emission controls in certain industrial sources and transportation (Y. Zhao et al., 2013), while $\mathrm{PM}_{2.5}$ concentrations have been increasing in recent years (Fig. 8). The result emphasizes that the ambient $\mathrm{PM}_{2.5}$ level is determined not only by primary particle emissions, but also by secondary particle formation driven by emissions of precursors and enhanced atmospheric oxidation which appears to be playing an increasingly important role in PM pollution across the country.

\subsection{Evaluation of emission inventories based on the $(\mathrm{OC} / \mathrm{EC})_{\mathrm{pri}}$}

The validity of current emission inventories of carbonaceous aerosols is evaluated through available observations of OC / EC ratios. The following criteria are used to select observational data: (1) observation sites must be located in rural or remote areas that are more representative of regional pollution from emissions; (2) the ratio of primary OC and EC, $(\mathrm{OC} / \mathrm{EC})_{\text {pri }}$, must be provided or can be calculated based on the observations; and (3) the sampling period must be sufficient for evaluation of annual emissions. With these restrictions, the observational data suitable for (OC / EC) pri evaluation come mainly from X. Zhang et al. (2008) for 2006. As shown in Fig. 9, the value of (OC / EC) pri from given observational sites is indicated on the $x$ axis, while that from the estimated emissions for the province where the site is located is shown on the $y$ axis. The correlations of (OC / EC) pri between observations and emissions are then analyzed. Besides the emissions estimated in this work, other emission inventories for 2006 (Zhang et al., 2009; Kurokawa et al., 2013) and 2005 (Lei et al., 2011, as an approximation of 2006) are also included for comparison. Note that because these other inventories do not include emissions from open burning of biomass, we corrected their results by adding that part of emissions calculated by this work to their original totals.

As can be seen in Fig. 9, the data points based on provincial emissions estimated by this work, with a regression slope of 0.97 , are in best agreement with the $Y=X$ line, while the emission ratios $\left[(\mathrm{OC} / \mathrm{EC})_{\mathrm{emi}}\right]$ of the other inventories are $20-50 \%$ higher than the observed concentration ratios. The residual sum of squares (RSS), which measures the discrepancy of the data and the linear regression model, is calculated as well for all the inventories, and the lowest RSS (and thereby random error) is found for this work, at 1.18. The comparison thus indicates improved reliability and reduced uncertainty of our inventory, resulting largely from a more detailed classification of source categories and application of emission factors from local field measurements. The $(\mathrm{OC} / \mathrm{EC})_{\text {pri }}$ obtained from observations in Nanning is much lower than $(\mathrm{OC} / \mathrm{EC})_{\mathrm{emi}}$ for its province, Guangxi, estimated in this work (point $\mathrm{A}$ in Fig. 9). The deviation might result partly from the fact that the observation was actually conducted in an urban area but categorized as a rural measurement because of less intense emission activity in this relatively underdeveloped city, according to X. Zhang et al. (2008). It thus further implies the better representativeness of regional emission levels by observation at rural or remote sites. Excluding point A from the linear regressions analysis, the slope comparing the observations and emissions estimated by this work would change to 0.92, with an RSS reduced to 0.62, while those for Zhang et al. (2009), Lei et al. (2011), and REAS 2 are recalculated as 1.12, 1.27, and 1.35 , with RSSs of $1.58,1.36$, and 2.60 , respectively (not shown in Fig. 9).

Despite efforts to improve the emission estimation, the regression slopes comparing $\mathrm{OC} / \mathrm{EC}$ from emissions in this work to observations are less than 1.0. In particular, (OC / EC) pri obtained from observations at two sites, Longfengshan in Heilongjiang (point B) and Taiyangshan in Hunan (point C) are clearly larger than $(\mathrm{OC} / \mathrm{EC})_{\mathrm{emi}}$ in this work, but closer to those for other inventories. This deviation thus implies a possible underestimation of emissions for sources with a high $\mathrm{OC} / \mathrm{EC}$ ratio, e.g., combustion of biofuel/biomass waste in agricultural areas. As mentioned in Sect. 2.4, part of the uncertainty comes from a lack of sufficient evaluation of the representativeness and reliability of emission factors of biofuel use from limited domestic measurements. Another important reason for the relatively low OC emission results could be possible underestimation of biomass open burning in some areas. In the bottom-up method, the amount of biomass burning in clear fields depends significantly on one parameter: the ratio of burned crop wastes to the total produced. Existing investigations of this ratio, with its spatial distribution and temporal trends across the country, are far from sufficient, and piecemeal 
information from local government plans on renewable energy or constant values from individual surveys (e.g., Wang and Zhang, 2008) have to be applied in emission estimation, though they likely differ significantly from facts on the ground. For example, increased ratios of crop waste recycling and utilization (which imply decreased ratios of crop wastes burned in open fields) are suggested in the government plans from 2005 to 2012 in the YRD region, where the air quality is influenced heavily by open biomass burning in harvest season. According to fire counts and intensity observed by satellite with MODIS (Moderate Resolution Imaging Spectroradiometer; https://earthdata.nasa.gov/ data/near-real-time-data/firms), however, a growing trend of biomass burning is found for the region during the period (X. Huang et al., 2012). Moreover, relatively strong signals of fire intensity are indicated by MODIS for northeastern and south-central China, close to the observation sites of points $\mathrm{B}$ and $\mathrm{C}$ in Fig. 9, respectively, implying considerable influence of biomass burning on the ambient carbonaceous aerosol levels in those regions. To better understand the levels and trends of carbonaceous aerosol emissions in China, therefore, more observations from ground sites and satellites should be collected and incorporated into the framework of bottom-up emission estimation methods.

\section{Conclusions}

An updated emission inventory of anthropogenic OC and EC from China is developed with an improved source category framework. Due to fast growth of the economy and energy consumption, national emissions of primary carbonaceous aerosols are estimated to have increased 29 and $37 \%$ for OC and EC, respectively, from 2000 to 2012. Attributed mainly to incomplete combustion of solid fuels, the residential sector is the greatest contributor to emissions, with shares of total emissions estimated to range $74-78 \%$ for OC and $49-55 \%$ for EC, followed by industry (17-21\% for OC and 30-34\% for EC) and transportation (4-6\% for OC and $14-18 \%$ for EC). Higher emission intensities of carbonaceous particles but lower ratios of OC to EC emissions are estimated for northern provinces than southern ones. The updated emission factors incorporating the results from the most recent local field measurements are the main reason for differences in emission estimates between our study and other inventories. In particular, the relatively low emission factors of biofuel stoves based on domestic tests lead to clearly smaller OC emissions in this work than in most other studies.

Combining available observational studies across the country, a comprehensive picture of carbonaceous aerosol pollution is provided at the national scale. Higher concentrations of carbonaceous aerosols are found for northern and inland cities while lower ones are found for southern and coastal cities. Clear concentration gradients are shown for urban, rural, and remote sites, indicating the effects of anthro- pogenic activities on carbonaceous PM pollution. In contrast to urban sites, especially in northern cities where primary emissions of anthropogenic origin play a more important role in ambient OC levels, larger contributions of SOC to OC are estimated at rural and remote sites, attributed to more emissions of biofuel-originated OC and biogenic VOCs, and/or transport from aged aerosols. While higher concentrations occur in cold seasons for all of the carbonaceous aerosol species (OC, EC, and SOC), smaller seasonal variations are observed for SOC / OC, particularly at rural sites, implying accelerated atmospheric oxidation in summer. In urban and suburban areas, larger ratios of ambient $\mathrm{OC}$ to EC are observed in higher atmospheric $\mathrm{PM}_{2.5}$ concentrations, implying the increased contribution of SOC to heavy haze pollution. As a dominant source of OC, biomass burning is confirmed to play significant roles in the carbonaceous aerosol pollution and worsened air quality during harvest seasons.

The emission inventory is evaluated using available observations on ambient concentrations over the country. The estimate of increased annual national emissions is somewhat inconsistent with relatively stable ambient levels of carbonaceous aerosols for 2000-2010. Due to a lack of detailed information regarding emission sources, little consideration of inter-annual trends in emission factors, particularly in the residential sector, could be one of the reasons explaining the discrepancy. Through comparisons of (OC / EC) pri obtained from emissions and observations, the estimated emissions in this work are confirmed to better correlate with observations than other inventories, helping to validate the current work. However, the lower (OC / EC) pri from emissions than observations for some areas indicates that emissions of certain sources producing relatively large OC, e.g., biomass open burning, might be underestimated. More ground and satellite observations are thus encouraged, to be incorporated into the framework of bottom-up emission inventories to better understand the levels and trends of carbonaceous aerosol emissions from biomass burning.

\section{The Supplement related to this article is available online at doi:10.5194/acp-15-8657-2015-supplement.}

Acknowledgements. This work was sponsored by the Natural Science Foundation of China (41205110), Natural Science Foundation of Jiangsu (BK20140020 and BK2012310), Jiangsu Science and Technology Support Program (SBE2014070918) and Ministry of Education of China (20120091120019). Thanks also go to two anonymous reviewers for their very valuable comments to improve this work.

Edited by: J. Liggio 


\section{References}

Bo, Y., Cai, H., and Xie, S. D.: Spatial and temporal variation of historical anthropogenic NMVOCs emission inventories in China, Atmos. Chem. Phys., 8, 7297-7316, doi:10.5194/acp-8-72972008, 2008.

Bond, T. C., Streets, D. G., Yarber, K. F., Nelson, S. M., Woo, J. H., and Klimont, Z.: A technology-based global inventory of black and organic carbon emissions from combustion, J. Geophys. Res., 109, D14203, doi:10.1029/2003jd003697, 2004.

Bond, T. C., Bhardwaj, E., Dong, R., Jogani, R., Jung, S. K., Roden, C., Streets, D. G., and Trautmann, N. M.: Historical emissions of black and organic carbon aerosol from energy-related combustion, 1850-2000, Global Biogeochem. Cy., 21, GB2018, doi:10.1029/2006gb002840, 2007.

BP: Statistical Review of World Energy 2014, Pureprint Group Limited, UK, available at: http://www.bp.com/en/global/corporate/ about-bp/energy-economics/statistical-review-of-world-energy. html (last access: 21 March 2015), 2014.

Cao, G. L., Zhang, X. Y., Gong, S. L., and Zheng, F. C.: Investigation on emission factors of particulate matter and gaseous pollutants from crop residue burning, J. Environ. Sci., 20, 50-55, 2008.

Cao, J. J., Lee, S. C., Ho, K. F., Zhang, X. Y., Zou, S. C., Fung, K., Chow, J. C., and Watson, J. G.: Characteristics of carbonaceous aerosol in Pearl River Delta Region, China during 2001 winter period, Atmos. Environ., 37, 1451-1460, 2003 a.

Cao, J. J., Lee, S. C., Ho, K. F., Zou, S. C., Zhang, X. Y., and Pan, J. G.: Spatial and seasonal distributions of atmospheric carbonaceous aerosols in pearl river delta region, China, China Particuology, 1, 33-37, 2003b.

Cao, J. J., Lee, S. C., Ho, K. F., Zou, S. C., Fung, K., Li, Y., Watson, J. G., and Chow, J. C.: Spatial and seasonal variations of atmospheric organic carbon and elemental carbon in Pearl River Delta Region, China, Atmos. Environ., 38, 4447-4456, 2004.

Cao, J. J, Lee S. C., Li, Y., Chow, J. C., and Fung, K.: Characteristics and source apportionment of organic carbon and elemental carbon in fall and winter, 2003 for Xi' an, Progr. Natural Sci., 15, 1460-1466, 2005a (in Chinese).

Cao, J. J., Wu, F., Chow, J. C., Lee, S. C., Li, Y., Chen, S. W., An, Z. S., Fung, K. K., Watson, J. G., Zhu, C. S., and Liu, S. X.: Characterization and source apportionment of atmospheric organic and elemental carbon during fall and winter of 2003 in Xi'an, China, Atmos. Chem. Phys., 5, 3127-3137, doi:10.5194/acp-53127-2005, 2005b.

Cao, J. J., Lee, S. C., Chow, J. C., Watson, J. G., Ho, K. F., Zhang, R. J., Jin, Z. D., Shen, Z. X., Chen, G. C., Kang, Y. M., Zou, S. C., Zhang, L. Z., Qi, S. H., Dai, M. H., Cheng, Y., and $\mathrm{Hu}, \mathrm{K}$.: Spatial and seasonal distributions of carbonaceous aerosols over China, J. Geophys. Res., 112, D22S11, doi:10.1029/2006jd008205, 2007.

Castro, L. M., Pio, C. A., Harrison, R. M., and Smith, D. J. T.: Carbonaceous aerosol in urban and rural European atmospheres: estimation of secondary organic carbon concentrations, Atmos. Environ., 33, 2771-2781, 1999.

Chen, C., Wang, H. H., Zhang, W., Hu, D., Chen, L., and Wang, X. J.: High-resolution inventory of mercury emissions from biomass burning in China for 2000-2010 and a projection for 2020, J. Geophys. Res.-Atmos., 118, 12248-12256, doi:10.1002/2013jd019734, 2013.
Chen, Y., Xie, S. D., Luo, B., and Zhai, C. Z.: Characteristics and origins of carbonaceous aerosol in the Sichuan Basin, China, Atmos. Environ., 94, 215-223, 2014.

Chen, Y. J., Sheng, G. Y., Bi, X. H., Feng, Y. L., Mai, B. X., and Fu, J. M.: Emission Factors for Carbonaceous Particles and Polycyclic Aromatic Hydrocarbons from Residential Coal Combustion in China, Environ. Sci. Technol., 39, 1861-1867, 2005.

Chen, Y. J., Zhi, G. R., Feng, Y. L., Fu, J. M., Feng, J. L., Sheng, G. Y., and Simoneit, B. R. T.: Measurements of emission factors for primary carbonaceous particles from residential rawcoal combustion in China, Geophys. Res. Lett., 33, L20815, doi:10.1029/2006g1026966, 2006.

Chen, Y. J, Zhi, G. R, Feng, Y. L., Liu, D. Y., Zhang, G., Li, J., Sheng, G. Y., and Fu, J. M.: Measurements of Black and Organic Carbon Emission Factors for Household Coal Combustion in China: Implication for Emission Reduction, Environ. Sci. Technol., 43, 9495-9500, 2009.

Cheng, Y., He, K. B., Duan, F. K., Zheng, M., Du, Z. Y., Ma, Y. L., and Tan, J. H.: Ambient organic carbon to elemental carbon ratios: Influences of the measurement methods and implications, Atmos. Environ., 45, 2060-2066, 2011.

Cheng, Y., He, K. B., Duan, F. K., Du, Z. Y., Zheng, M., and Ma, Y. L.: Ambient organic carbon to elemental carbon ratios: influence of the thermal-optical temperature protocol and implications, Sci. Total Environ., 468-469, 1103-1111, 2014.

Cheng, Z., Wang, S., Fu, X., Watson, J. G., Jiang, J., Fu, Q., Chen, C., Xu, B., Yu, J., Chow, J. C., and Hao, J.: Impact of biomass burning on haze pollution in the Yangtze River delta, China: a case study in summer 2011, Atmos. Chem. Phys., 14, 45734585, doi:10.5194/acp-14-4573-2014, 2014.

Chou, C. C.-K., Lee, C. T., Cheng, M. T., Yuan, C. S., Chen, S. J., Wu, Y. L., Hsu, W. C., Lung, S. C., Hsu, S. C., Lin, C. Y., and Liu, S. C.: Seasonal variation and spatial distribution of carbonaceous aerosols in Taiwan, Atmos. Chem. Phys., 10, 9563-9578, doi:10.5194/acp-10-9563-2010, 2010.

Dan, M., Zhuang, G. S., Li, X. X., Tao, H. R., and Zhuang, Y. H.: The characteristics of carbonaceous species and their sources in $\mathrm{PM}_{2.5}$ in Beijing, Atmos. Environ., 38, 3443-3452, 2004.

Day, M. C., Zhang, M., and Pandis, S. N.: Evaluation of the ability of the EC tracer method to estimate secondary organic carbon, Atmos. Environ., 112, 317-325, 2015.

Ding, X., Wang, X. M., Gao, B., Fu, X. X., He, Q. F., Zhao, X. Y., Yu, J. Z., and Zheng, M.: Tracer-based estimation of secondary organic carbon in the Pearl River Delta, south China, J. Geophys. Res., 117, D05313, doi:10.1029/2011jd016596, 2012.

Duan, F. K., He, K. B., Ma, Y. L., Jia, Y. T., Yang, F. M, Lei, Y., Tanaka, S., and Okuta, T.: Characteristics of carbonaceous aerosols in Beijing, China, Chemosphere, 60, 355-364, 2005.

Duan, J. C., Tan, J. H., Cheng, D. X., Bi, X. H., Deng, W. J., Sheng, G. Y., Fu, J. M., and Wong, M. H.: Sources and characteristics of carbonaceous aerosol in two largest cities in Pearl River Delta Region, China, Atmos. Environ., 41, 2895-2903, 2007.

Engling, G. and Gelencser, A.: Atmospheric Brown Clouds: From Local Air Pollution to Climate Change, Elements, 6, 223-228, 2010.

Feng, J. L., Chan, C. K., Fang, M., Hu, M., He, L. Y., and Tang, X. Y.: Characteristics of organic matter in $\mathrm{PM}_{2.5}$ in Shanghai, Chemosphere, 64, 1393-1400, 2006a. 
Feng, J. L., Hu, M., Chan, C. K., Lau, P. S., Fang, M., He, L. Y., and Tang, X. Y.: A comparative study of the organic matter in $\mathrm{PM}_{2.5}$ from three Chinese megacities in three different climatic zones, Atmos. Environ., 40, 3983-3994, 2006b.

Feng, J. L., Li, M., Zhang, P., Gong, S. Y., Zhong, M., Wu, M. H., Zheng, M., Chen, C. H., Wang, H. L., and Lou, S. R.: Investigation of the sources and seasonal variations of secondary organic aerosols in $\mathrm{PM}_{2.5}$ in Shanghai with organic tracers, Atmos. Environ., 79, 614-622, 2013.

Feng, Y., Chen, Y., Guo, H., Zhi, G., Xiong, S., Li, J., Sheng, G., and $\mathrm{Fu}, \mathrm{J}$. : Characteristics of organic and elemental carbon in $\mathrm{PM}_{2.5}$ samples in Shanghai, China, Atmos. Res., 92, 434-442, 2009.

Folidori, A., Turpin, B. J., Lim, H. J., Cabada, J. C., Subramanian, R., Pandis, S. N., and Robinson, A. L.: Local and regional secondary organic aerosol: Insights from a Year of semi-continuous carbon measurments at Pittsburgh, Aerosol Sci. Technol., 40, 861-872, 2006.

Fu, M., Ding, Y., Ge, Y., Yu, L., Yin, H., Ye, W., and Liang, B.: Real-world emissions of inland ships on the Grand Canal, China, Atmos. Environ., 81, 222-229, 2013.

Fu, T.-M., Cao, J. J., Zhang, X. Y., Lee, S. C., Zhang, Q., Han, Y. M., Qu, W. J., Han, Z., Zhang, R., Wang, Y. X., Chen, D., and Henze, D. K.: Carbonaceous aerosols in China: top-down constraints on primary sources and estimation of secondary contribution, Atmos. Chem. Phys., 12, 2725-2746, doi:10.5194/acp12-2725-2012, 2012.

Ge, S., Xu, X., Chow, J. C., Watson, J., Sheng, Q., Liu, W., Bai Z. P., Zhu T., and Zhang, J. F.: Emissions of air pollutants from household stoves: honeycomb coal versus coal cake. Environ. Sci. Technol., 38, 4612-4618, 2004.

Gelencsér, A., May, B., Simpson, D., Sánchez-Ochoa, A., Kasper-Giebl, A., Puxbaum, H., Caseiro, A., Pio, C., and Legrand, M.: Source apportionment of $\mathrm{PM}_{2.5}$ organic aerosol over Europe: Primary/secondary, natural/anthropogenic, and fossil/biogenic origin, J. Geophys. Res., 112, D23S04, doi:10.1029/2006jd008094, 2007.

Gu, J. X., Bai, Z. P., Liu, A. X., Wu, L. P., Xie, Y. Y., Li, W. F., Dong, H. Y., and Zhang, X.: Characterization of Atmospheric Organic Carbon and Element Carbon of $\mathrm{PM}_{2.5}$ and $\mathrm{PM}_{10}$ at Tianjin, China, Aerosol Air Qual. Res, 10, 167-176, 2010.

Han, Y. M., Han, Z. W., Cao, J. J., Chow, J. C., Watson, J. G., An, Z. S., Liu, S. X., and Zhang, R. J.: Distribution and origin of carbonaceous aerosol over a rural high-mountain lake area, Northern China and its transport significance, Atmos. Environ., 42, 2405-2414, 2008.

Harrison, R. M. and Yin, J.: Sources and processes affecting carbonaceous aerosol in central England, Atmos. Environ., 42, 1413-1423, 2008.

Hou, B., Zhuang, G., Zhang, R., Liu, T., Guo, Z., and Chen, Y.: The implication of carbonaceous aerosol to the formation of haze: revealed from the characteristics and sources of OC / EC over a mega-city in China, J. Hazard. Mater., 190, 529-536, 2011.

Hu, D., Bian, Q., Lau, A. K. H., and Yu, J. Z.: Source apportioning of primary and secondary organic carbon in summer $\mathrm{PM}_{2.5}$ in Hong Kong using positive matrix factorization of secondary and primary organic tracer data, J. Geophys. Res., 115, D16204, doi:10.1029/2009jd012498, 2010.

Hu, W. W., Hu, M., Deng, Z. Q., Xiao, R., Kondo, Y., Takegawa, N., Zhao, Y. J., Guo, S., and Zhang, Y. H.: The characteristics and origins of carbonaceous aerosol at a rural site of PRD in summer of 2006, Atmos. Chem. Phys., 12, 1811-1822, doi:10.5194/acp12-1811-2012, 2012.

Huang, H., Ho, K. F., Lee, S. C., Tsang, P. K., Ho, S. S. H., Zou, C. W., Zou, S. C., Cao, J. J., and Xu, H. M.: Characteristics of carbonaceous aerosol in $\mathrm{PM}_{2.5}$ : Pearl Delta River Region, China, Atmos. Res., 104-105, 227-236, 2012.

Huang, J., Kang, S., Shen, C., Cong, Z., Liu, K., Wang, W., and Liu, L.: Seasonal variations and sources of ambient fossil and biogenic-derived carbonaceous aerosols based on ${ }^{14} \mathrm{C}$ measuements in Lhasa Tibet, Atmos. Res., 96, 553-559, 2010.

Huang, L., Yuan, C. S., Wang, G., and Wang, K.: Chemical characteristics and source apportionment of $\mathrm{PM}_{10}$ during a brown haze episode in Harbin, China, Particuology, 9, 32-38, 2011.

Huang, R. J., Zhang, Y., Bozzetti, C., Ho, K. F., Cao, J. J., Han, Y., Daellenbach, K. R., Slowik, J. G., Platt, S. M., Canonaco, F., Zotter, P., Wolf, R., Pieber, S. M., Bruns, E. A., Crippa, M., Ciarelli, G., Piazzalunga, A., Schwikowski, M., Abbaszade, G., SchnelleKreis, J., Zimmermann, R., An, Z., Szidat, S., Baltensperger, U., Haddad, I. E., and Prevot, A. S.: High secondary aerosol contribution to particulate pollution during haze events in China, Nature, 514, 218-222, 2014.

Huang, X., Song, Y., Li. M., Li, J., and Zhu, T.: Harvest season, high polluted season in East China, Envrion. Res. Lett., 7, 044033, doi:10.1088/1748-9326/7/4/044033, 2012.

Huang, X., Xue, L., Tian X., Shao, W., Sun, T., Gong, Z., Ju, W., Jiang, B., Hu, M., and He, L.: Highly time-resolved carbonaceous aerosol characterization in Yangtze River Delta of China: Composition, mixing state and secondary formation, Atmos. Environ., 64, 200-207, 2013.

Huo, H., Yao, Z., Zhang, Y., Shen, X., Zhang, Q., and He, K.: Onboard measurements of emissions from diesel trucks in five cities in China, Atmos. Environ., 54, 159-167, 2012.

Jung, J., Lee, H., Kim, Y. J., Liu, X., Zhang, Y., Gu, J., and Fan, S.: Aerosol chemistry and the effect of aerosol water content on visibility impairment and radiative forcing in Guangzhou during the 2006 Pearl River Delta campaign, J. Environ. Manage., 90, 3231-3244, 2009.

Kim, K. H., Sekiguchi, K., Furuuchi, M., and Sakamoto, K.: Seasonal variation of carbonaceous and ionic components in ultrafine and fine particles in an urban area of Japan, Atmos. Environ., 45, 1581-1590, 2011.

Klimont, Z., Cofala, J., Xing, J., Wei, W., Zhang, C., Wang, S., Kejun, J., Bhandari, P., Mathur, R., Purohit, P., Rafaj, P., Chambers, A., Amann, M., and Hao, J.: Projections of $\mathrm{SO}_{2}, \mathrm{NO}_{x}$ and carbonaceous aerosols emissions in Asia, Tellus B, 61, 602-617, 2009.

Kong, S., Han, B., Bai, Z., Chen, L., Shi, J., and Xu, Z.: Receptor modeling of $\mathrm{PM}_{2.5}, \mathrm{PM}_{10}$ and TSP in different seasons and longrange transport analysis at a coastal site of Tianjin, China, Sci. Total Environ., 408, 4681-4694, 2010.

Kurokawa, J., Ohara, T., Morikawa, T., Hanayama, S., JanssensMaenhout, G., Fukui, T., Kawashima, K., and Akimoto, H.: Emissions of air pollutants and greenhouse gases over Asian regions during 2000-2008: Regional Emission inventory in ASia (REAS) version 2, Atmos. Chem. Phys., 13, 11019-11058, doi:10.5194/acp-13-11019-2013, 2013. 
Lei, Y., Zhang, Q., He, K. B., and Streets, D. G.: Primary anthropogenic aerosol emission trends for China, 1990-2005, Atmos. Chem. Phys., 11, 931-954, doi:10.5194/acp-11-931-2011, 2011.

Li, B., Zhang, J., Zhao, Y., Yuan, S. Y., Zhao, Q. Y., Shen, G. F., and $\mathrm{Wu}, \mathrm{H}$. S.: Seasonal variation of urban carbonaceous aerosols in a typical city Nanjing in Yangtze River Delta, China, Atmos. Environ., 106, 223-231, 2015.

Li, P. H., Han, B., Huo, J., Lu, B., Ding, X., Chen, L., Kong, S. F., Bai, Z. P., and Wang, B.: Characterization, Meteorological Influences and Source Identification of Carbonaceous Aerosols during the Autumn-winter Period in Tianjin, China, Aerosol Air Qual. Res., 12, 283-294, 2012.

Li, W. and Bai, Z.: Characteristics of organic and elemental carbon in atmospheric fine particles in Tianjin, China, Particuology, 7, 432-437, 2009

Li, X., Wang, S., Duan, L., Hao, J., Li, C., Chen, Y., and Yang, L.: Particulate and trace gas emissions from open burning of wheat straw and corn stover in China, Environ. Sci. Technol., 41, 60526058, 2007.

Li, X., Wang, S., Duan, L., Hao, J., and Nie, Y.: Carbonaceous aerosol emissions from household biofuel combustion in China, Environ. Sci. Technol., 43, 6076-6081, 2009.

Li, X., Wang, L., Wang, Y., Wen, T., Yang, Y., Zhao, Y., and Wang, Y.: Chemical composition and size distribution of airborne particulate matters in Beijing during the 2008 Olympics, Atmos. Environ., 50, 278-286, 2012.

Li, Y. C., Yu, J. Z., Ho, S. S. H., Yuan, Z., Lau, A. K. H., and Huang, $X$. F.: Chemical characteristics of $\mathrm{PM}_{2.5}$ and organic aerosol source analysis during cold front episodes in Hong Kong, China, Atmos. Res., 118, 41-51, 2012.

Lin, P., Hu, M., Deng, Z., Slanina, J., Han, S., Kondo, Y., Takegawa, N., Miyazaki, Y., Zhao, Y., and Sugimoto N.: Seasonal and diurnal variations of organic carbon in $\mathrm{PM}_{2.5}$ in Beijing and the estimation of secondary organic carbon, J. Geophys. Res., 114, D00G11, doi:10.1029/2008JD010902, 2009.

Lu, Z., Streets, D. G., Zhang, Q., Wang, S., Carmichael, G. R., Cheng, Y. F., Wei, C., Chin, M., Diehl, T., and Tan, Q.: Sulfur dioxide emissions in China and sulfur trends in East Asia since 2000, Atmos. Chem. Phys., 10, 6311-6331, doi:10.5194/acp-106311-2010, 2010.

Lu, Z., Zhang, Q., and Streets, D. G.: Sulfur dioxide and primary carbonaceous aerosol emissions in China and India, 1996-2010, Atmos. Chem. Phys., 11, 9839-9864, doi:10.5194/acp-11-98392011, 2011.

Matthias-Maser, S. and Jaenicke, R.,: The size distribution of primary biological aerosol particles in the multiphase atmosphere, Aerobiologia, 16, 207-210, 2000.

Mauderly, J. L. and Chow, J. C.: Health effects of organic aerosols, Inhalation Toxicol., 20, 257-288, 2008.

National Bureau of Statistics (NBS): China Energy Statistical Yearbook 2001-2013, China Statistics Press, Beijing, China, 2013a (in Chinese).

National Bureau of Statistics (NBS): China Industry Economy Statistical Yearbook 2001-2013, China Statistics Press, Beijing, China, 2013b (in Chinese).

Niu, Z., Zhang, F., Chen, J., Yin, L., Wang, S., and Xu, L.: Carbonaceous species in $\mathrm{PM}_{2.5}$ in the coastal urban agglomeration in the Western Taiwan Strait Region, China, Atmos. Res., 122, 102-110, 2013.
Ohara, T., Akimoto, H., Kurokawa, J., Horii, N., Yamaji, K., Yan, X., and Hayasaka, T.: An Asian emission inventory of anthropogenic emission sources for the period 1980-2020, Atmos. Chem. Phys., 7, 4419-4444, doi:10.5194/acp-7-4419-2007, 2007.

Park, S. S., Kim, Y. J., and Fung, K.: Characteristics of $\mathrm{PM}_{2.5}$ carbonaceous aerosol in the Sihwa industrial area, South Korea, Atmos. Environ., 35, 657-665, 2001.

Pio, C., Cerqueira, M., Harrison, R. M., Nunes, T., Mirante, F., Alves, C., Oliveira, C., Sanchez de la Campa, A., Artíñano, B., and Matos, M.: OC / EC ratio observations in Europe: Rethinking the approach for apportionment between primary and secondary organic carbon, Atmos. Environ., 45, 6121-6132, 2011.

Qin, Y. and Xie, S. D.: Spatial and temporal variation of anthropogenic black carbon emissions in China for the period 19802009, Atmos. Chem. Phys., 12, 4825-4841, doi:10.5194/acp-124825-2012, 2012.

Qin, Y., Kim, E., and Hopke, P. K.: The concentrations and sources of $\mathrm{PM}_{2.5}$ in metropolitan New York City, Atmos. Environ., 40, 312-332, 2006.

Qu, W. J., Zhang, X. Y., Arimoto, R., Wang, Y. Q., Wang, D., Sheng, L. F., and Fu, G.: Aerosol background at two remote CAWNET sites in western China, Sci. Total Environ., 407, 3518-3529, 2009.

Schauer, J. J., Mader, B. T., Deminter, J. T., Heidemann, G., Bae, M. S., Seinfeld, J. H., Flagan, R. C., Cary, R. A., Smith, D., Huebert, B. J., Bertram, T., Howell, S., Kline, J. T., Quinn, P., Bates, T., Turpin, B., Lim, H. J., Yu, J. Z., Yang, H., and Keywood, M. D.: ACE-Asia Intercomparison of a thermal-optical method for the determination of partcile-phase organic and elemental carbon, Environ. Sci. Technol., 37, 993-1001, 2003.

Schmid, H., Laskus, L., Abraham, H. J., Baltensperger, U., Lavanchy, V., Bizjak, M., Burba, P., Cachier, H., Crow, D., Chow, J., Gnauk, T., Even, A., ten Brink, H. M., Gisen, K.-P., Hitzenberger, R., Hueglin, C., Maenhaut, W., Pio, C., Carvalho, A., Putaud, J.P., Toom-Sauntry, D., and Puxbaum, H.: Results of the "carbon concerence" internaitonal aerosol carbon round robin test stage I, Atmos. Environ., 35, 2111-2121, 2001.

Shen, G. F., Yang, Y., Wang, W., Tao, S., Zhu, C., Min, Y., Xue, M., Ding, J., Wang, B., Wan, R., Shen, H., Li, W., Wang, X., and Russell, A. G.: Emission factors of particulate matter and elemental carbon for crop residues and coals burned in typical household stoves in China, Environ. Sci. Technol., 44, 7157-7162, 2010.

Shen G. F., Wei, S. Y., Wei, W., Zhang, Y. Y., Min, Y. J., Wang, B., W., Wang, R., Li, W., Shen, H. Z., Huang, Y., Yang, Y. F., Wang W., Wang X. L., Wang X. J., and Tao S.: Emission factors, size distributions, and emission inventories of carbonaceous particulate matter from residential wood combustion in rural China, Environ. Sci. Technol., 46, 4207-4214, 2012.

Shen, G. F., Xue, M., Wei, S., Chen, Y., Zhao, Q., Li, B., Wu, H., and Tao, S.: Influence of fuel moisture, charge size, feeding rate and air ventilation conditions on the emissions of PM, OC, EC, parent PAHs, and their derivatives from residential wood combustion, $\mathrm{J}$. Environ. Sci., 25, 1808-1816, 2013.

Streets, D. G., Gupta, S., Waldhof, S. T., Wang, M. Q., Bond, T. C., and Bo, Y.: Black Carbon Emission in China, Atmos. Environ., 35, 4281-4296, 2001. 
Streets, D. G., Bond, T. C., Carmichael, G. R., Fernands, S. D., Fu, Q., He, D., Klimont, Z., Nelson, S. M., Tsai, N. Y., Wang, M. Q., Woo, J.-H., and Yarber, K. F.: An inventory of gaseous and primary aerosol emissions in Asia in the year 2000, J. Geophys. Res., 108, D218809, doi:10.1029/2002jd003093, 2003.

Turpin, B. J. and Lim, H. J.: Species Contributions to PM $_{2.5}$ Mass Concentrations: Revisiting Common Assumptions for Estimating Organic Mass, Aerosol Sci. Technol., 35, 602-610, 2001.

Wang, G., Wei. N., Liu, W., Lin, J., Fan, X.,Yao, J., Geng, Y., Li, Y., and Li, Y.: Size distributions of organic carbon (OC) and elemental carbon (EC) in Shanghai atmospheric particles, Environ. Sci., 31, 1993-2001, 2010 (in Chinese).

Wang, J. Z., Gong, S. L., Zhang, X. Y., Yang, Y. Q., Hou, Q., Zhou, C. H., and Wang, Y. Q.: A parameterized method for air-quality diagnosis and its applications, Adv. Meteorol., 2012, 238589, doi:10.1155/2012/238589, 2012.

Wang, Q. Y., Cao, J. J., Shen, Z. X., Tao, J., Xiao, S., Luo, L., He, Q. Y., and Tang X. Y.: Chemical characteristics of $\mathrm{PM}_{2.5}$ during dust storms and air pollution events in Chengdu, China, Particuology, 11, 70-77, 2013.

Wang, R., Tao, S., Wang, W., Liu, J., Shen, H., Shen, G., Wang, B., Liu, X., Li, W., Huang, Y., Zhang, Y., Lu, Y., Chen, H., Chen, Y., Wang, C., Zhu, D., Wang, X., Li, B., Liu, W., and Ma, J.: Black carbon emissions in China from 1949 to 2050, Environ. Sci. Technol., 46, 7595-7603, 2012.

Wang, S. X. and Zhang, C. Y.: Spatial and temporal distribution of air pollutant emissions from open burning of crop residues in China, Sciencepaper Online, 3, 329-333, 2008 (in Chinese).

Wang, S. X., Zhao, X. J., Li, X. H., Wei, W., and Hao, J. M.: Emission characteristics of fine particles from grate firing boilers, Environ. Sci., 30, 963-968, 2009 (in Chinese).

Wang, W., Jing, L., Zhan, J., Wang, B., Zhang, D. P., Zhang, H. W., Wang, D. Q., Yang, Y., Zhao, J., Sun, Y. F., Bi X. H., Wang, X. T., and Feng, J. L.: Nitrated polycyclic aromatic hydrocarbon pollution during the Shanghai World Expo 2010, Atmos. Environ., 89, 242-248, 2014.

Wang, Y., Dong Y. P., Feng, J. L., Guan, J. J., Zhao, W., and Li, H. J.: Characteristics and Influencing Factors of Carbonaceous Aerosols in PM2.5 in Shanghai, China, Environ. Sci., 31, 17551761, 2010 (in Chinese).

Watson, J. G., Chow, J. C., and Houck, J. E.: PM 2.5 chemical source profiles for vehicle exhaust, vegetative burning, geological material, and coal burning in Northwestern Colorado during 1995, Chemosphere, 43, 1141-1151, 2001.

Wei, S., Shen, G., Zhang, Y., Xue, M., Xie, H., Lin, P., Chen, Y., Wang, X., and Tao, S.: Field measurement on the emissions of $\mathrm{PM}, \mathrm{OC}, \mathrm{EC}$ and PAHs from indoor crop straw burning in rural China, Environ. Pollut., 184, 18-24, 2014.

Wei, W.: Study on current and future anthropogenic emissions of volatile organic compounds in China, Ph. D thesis,, Tsinghua university, Beijing, 2009 (in Chinese).

Wu, M., Guo, Z., Liu, F., Lu, X., Liu, J., and Ren, Y.: Pollution characteristics and influencing factors of organic and elemental carbon in $\mathrm{PM}_{2.1}$ in Nanjing, China Environmental Science, 33, 1160-1166, 2013 (in Chinese).

Wu, Y., Zhang, S. J., Li, M. L., Ge, Y. S., Shu, J. W., Zhou, Y., Xu, Y. Y., Hu, J. N., Liu, H., Fu, L. X., He, K. B., and Hao, J. M.: The challenge to NOx emission control for heavy-duty diesel vehicles in China, Atmos. Chem. Phys., 12, 9365-9379, doi:10.5194/acp12-9365-2012, 2012.

Yang, F., Huang, L., Duan, F., Zhang, W., He, K., Ma, Y., Brook, J. R., Tan, J., Zhao, Q., and Cheng, Y.: Carbonaceous species in $\mathrm{PM}_{2.5}$ at a pair of rural/urban sites in Beijing, 2005-2008, Atmos. Chem. Phys., 11, 7893-7903, doi:10.5194/acp-11-78932011, 2011a.

Yang, F., Huang, L., Sharma, S., Brook, J. R., Zhang, W., Li, S.-M., and Tan, J.: Two-year observations of fine carbonaceous particles in variable sampling intervals, Atmos. Environ., 45, 2418-2426, 2011b.

Yang, L., Zhou, X., Wang, Z., Zhou, Y., Cheng, S., Xu, P., Gao, X., Nie, W., Wang, X., and Wang, W.: Airborne fine particulate pollution in Jinan, China: Concentrations, chemical compositions and influence on visibility impairment, Atmos. Environ. 55, 506-514, 2012.

Yu, Y., Xie, F., Lu, X., Zhu, Z., and Shu, Y.: The environmental air quality condition and the reason analysis during the Asian Youth Games of Nanjing, Environ. Monitor. Forewar., 6, 5-17, 2014 (in Chinese).

Yuan, Z. B., Yu, J. Z., Lau, A. K. H., Louie, P. K. K., and Fung, J. C. H.: Application of positive matrix factorization in estimating aerosol secondary organic carbon in Hong Kong and its relationship with secondary sulfate, Atmos. Chem. Phys., 6, 25-34, doi:10.5194/acp-6-25-2006, 2006.

Zhang, F., Zhao, J., Chen, J., Xu, Y., and Xu, L.: Pollution characteristics of organic and elemental carbon in $\mathrm{PM}_{2.5}$ in Xiamen, China, J. Environ. Sci., 23, 1342-1349, 2011.

Zhang, F., Xu, L., Chen, J., Chen, X., Niu, Z., Lei, T., Li, C., and Zhao, J.: Chemical characteristics of $\mathrm{PM}_{2.5}$ during haze episodes in the urban of Fuzhou, China, Particuology, 11, 264-272, 2013.

Zhang, J., He, K. B., Shi, X. Y., and Zhao, Y.: Effect of SME biodiesel blends on $\mathrm{PM}_{2.5}$ emission from a heavy-duty engine, Atmos. Environ., 43, 2442-2448, 2009a.

Zhang, J., He, K. B., Ge, Y. S., and Shi, X. Y.: Influence of fuel sulfur on the characterization of $\mathrm{PM}_{10}$ from a diesel engine, Fuel, 88, 504-510, 2009b.

Zhang, Q., Streets, D. G., Carmichael, G. R., He, K. B., Huo, H., Kannari, A., Klimont, Z., Park, I. S., Reddy, S., Fu, J. S., Chen, D., Duan, L., Lei, Y., Wang, L. T., and Yao, Z. L.: Asian emissions in 2006 for the NASA INTEX-B mission, Atmos. Chem. Phys., 9, 5131-5153, doi:10.5194/acp-9-5131-2009, 2009.

Zhang, Q., He, K. B., and Huo, H.: Cleaning China's air, Nature, 484, 161-162, 2012.

Zhang, R. J., Cao, J. J., Lee, S. C., Shen, Z. X., and Ho, K. F.: Carbonaceous aerosols in $\mathrm{PM}_{10}$ and pollution gases in winter in Beijing, J. Environ. Sci., 19, 564-571, 2007.

Zhang, X. Y., Wang, Y. Q., Zhang, X. C., Guo, W., and Gong S. L.: Carbonaceous aerosol composition over various regions of China during 2006, J. Geophys. Res., 113, D14111, doi:10.1029/2007JD009525, 2008.

Zhang, X. Y., Wang, Y. Q., Niu, T., Zhang, X. C., Gong, S. L., Zhang, Y. M., and Sun, J. Y.: Atmospheric aerosol compositions in China: spatial/temporal variability, chemical signature, regional haze distribution and comparisons with global aerosols, Atmos. Chem. Phys., 12, 779-799, doi:10.5194/acp12-779-2012, 2012.

Zhang, X. Y., Sun, J. Y., Wang, Y. Q., Li, W. J., Zhang, Q., Wang, W. G., Quan, J. N., Cao, G. L., Wang, J. Z., Yang, Y. Q., and Zhang, 
Y. M.: Factors contributing to haze and fog in China, Chin. Sci. Bull., 58, 1178-1187, 2013.

Zhang, Y., Schauer, J. J., Zhang, Y., Zeng, L., Wei, Y., Liu, Y., and Shao, M.: Characteristics of particulate carbon emissions from real-world Chinese coal combustion, Environ. Sci. Technol., 42, 5068-5073, 2008.

Zhang, Z., Engling, G., Lin, C.-Y., Chou, C. C. K., Lung, S.-C. C., Chang, S.-Y., Fan, S., Chan, C.-Y., and Zhang, Y.-H.: Chemical speciation, transport and contribution of biomass burning smoke to ambient aerosol in Guangzhou, a mega city of China, Atmos. Environ., 44, 3187-3195, doi:10.1016/j.atmosenv.2010.05.024, 2010.

Zhao, P., Dong, F., Yang, Y., He, D., Zhao, X., Zhang, W., Yao, Q., and Liu, H.: Characteristics of carbonaceous aerosol in the region of Beijing, Tianjin, and Hebei, China, Atmos. Environ., 71, 389-398, 2013.

Zhao, Y., Nielsen, C. P., Lei, Y., McElroy, M. B., and Hao, J.: Quantifying the uncertainties of a bottom-up emission inventory of anthropogenic atmospheric pollutants in China, Atmos. Chem. Phys., 11, 2295-2308, doi:10.5194/acp-11-2295-2011, 2011.

Zhao, Y., Nielsen, C. P., McElroy, M. B., Zhang, L., and Zhang, J.: CO emissions in China: Uncertainties and implications of improved energy efficiency and emission control, Atmos. Environ., 49, 103-113, 2012.
Zhao, Y., Zhang, J., and Nielsen, C. P.: The effects of recent control policies on trends in emissions of anthropogenic atmospheric pollutants and CO2 in China, Atmos. Chem. Phys., 13, 487-508, doi:10.5194/acp-13-487-2013, 2013.

Zheng, M., Wang, F., Hagler, G. S. W., Hou, X., Bergin, M., Cheng, Y., Salmon, L. G., Schauer, J. J., Louie, P. K. K., Zeng, L., and Zhang, Y.: Sources of excess urban carbonaceous aerosol in the Pearl River Delta Region, China, Atmos. Environ., 45, 11751182, 2011.

Zhi, G., Chen, Y., Feng, Y., Xiong, S., Li, J., Zhang, G., Sheng, G., and Fu, J.: Emission characteristics of carbonaceous particles from various residential coal-stoves in China, Environ. Sci. Technol., 42, 3310-3315, 2008.

Zhi, G., Peng, C., Chen, Y., Liu, D., Sheng, G., and Fu, J.: Deployment of coal briquettes and improved stoves: possibly an option for both environment and climate, Environ. Sci. Technol., 43, 5586-5591, 2009. 